\title{
Diversity, Biogeography, and Biodegradation Potential of Actinobacteria in the Deep-Sea Sediments along the Southwest Indian Ridge
}

\section{OPEN ACCESS}

Edited by:

Mark Alexander Lever,

ETH Zurich, Switzerland

Reviewed by:

William D. Orsi,

Lüdwig-Maximilians University of

Munich, Germany

Sean Patrick Jungbluth,

University of Southern California, USA

*Correspondence:

Ying Huang

huangy@im.ac.cn

${ }^{\dagger}$ Present Address:

Lijun Xi,

State Key Laboratory of Heavy Oil

Processing and Centre for

Bioengineering and Biotechnology,

China University of Petroleum

Qingdao, China

Specialty section:

This article was submitted to

Extreme Microbiology,

a section of the journal

Frontiers in Microbiology

Received: 22 May 2016 Accepted: 15 August 2016

Published: 29 August 2016

Citation:

Chen P, Zhang L, Guo X, Dai X, Liu L,

$X i L$, Wang J, Song L, Wang $Y$, Zhu $Y$, Huang $L$ and Huang $Y$ (2016) Diversity, Biogeography, and Biodegradation Potential of Actinobacteria in the Deep-Sea Sediments along the Southwest Indian

Ridge. Front. Microbiol. 7:1340. doi: 10.3389/fmicb.2016.01340
Ping Chen ${ }^{1,2}$, Limin Zhang ${ }^{1}$, Xiaoxuan Guo ${ }^{1,2}$, Xin Dai ${ }^{1,2}, \mathrm{Li} \mathrm{Liu}^{3}$, Lijun Xi ${ }^{1+}$, Jian Wang ${ }^{1}$, Lei Song ${ }^{4}$, Yuezhu Wang ${ }^{5}$, Yaxin Zhu ${ }^{1}$, Li Huang ${ }^{1,2}$ and Ying Huang ${ }^{1 *}$

\footnotetext{
1 State Key Laboratory of Microbial Resources, Institute of Microbiology, Chinese Academy of Sciences, Beijing, China, ${ }^{2}$ College of Life Sciences, University of Chinese Academy of Sciences, Beijing, China, ${ }^{3}$ Information Network Center, Institute of Microbiology, Chinese Academy of Sciences, Beijing, China, ${ }^{4}$ China General Microbiological Culture Collection Center, Institute of Microbiology, Chinese Academy of Sciences, Beijing, China, ${ }^{5}$ Shanghai-MOST Key Laboratory of Disease and Health Genomics, Chinese National Human Genome Center at Shanghai, Shanghai, China
}

The phylum Actinobacteria has been reported to be common or even abundant in deep marine sediments, however, knowledge about the diversity, distribution, and function of actinobacteria is limited. In this study, actinobacterial diversity in the deep sea along the Southwest Indian Ridge (SWIR) was investigated using both 16S rRNA gene pyrosequencing and culture-based methods. The samples were collected at depths of $1662-4000 \mathrm{~m}$ below water surface. Actinobacterial sequences represented $1.2-9.1 \%$ of all microbial $16 \mathrm{~S}$ rRNA gene amplicon sequences in each sample. A total of 5 actinobacterial classes, 17 orders, 28 families, and 52 genera were detected by pyrosequencing, dominated by the classes Acidimicrobiia and Actinobacteria. Differences in actinobacterial community compositions were found among the samples. The community structure showed significant correlations to geochemical factors, notably $\mathrm{pH}$, calcium, total organic carbon, total phosphorus, and total nitrogen, rather than to spatial distance at the scale of the investigation. In addition, 176 strains of the Actinobacteria class, belonging to 9 known orders, 18 families, and 29 genera, were isolated. Among these cultivated taxa, 8 orders, 13 families, and 15 genera were also recovered by pyrosequencing. At a $97 \% 16 \mathrm{~S}$ rRNA gene sequence similarity, the pyrosequencing data encompassed $77.3 \%$ of the isolates but the isolates represented only $10.3 \%$ of the actinobacterial reads. Phylogenetic analysis of all the representative actinobacterial sequences and isolates indicated that at least four new orders within the phylum Actinobacteria were detected by pyrosequencing. More than half of the isolates spanning 23 genera and all samples demonstrated activity in the degradation of refractory organics, including polycyclic aromatic hydrocarbons and polysaccharides, suggesting their potential ecological functions and biotechnological applications for carbon recycling.

Keywords: community structure, cultivation, biodegradation, marine actinobacteria, microbial diversity, pyrosequencing, Southwest Indian Ridge 


\section{INTRODUCTION}

The phylum Actinobacteria is composed of a large group of morphologically and physiologically diverse Gram-positive bacteria with high genomic $\mathrm{G}+\mathrm{C}$ contents, which are ubiquitous in nature (Ensign, 1992; Goodfellow et al., 2012). Members of this phylum are also successful colonizers of different extreme environments, often occurring as abundant populations (Bull, 2011). This phylum has been found to be one of the top five most abundant bacterial phyla in the deep ocean (Zinger et al., 2011; Yilmaz et al., 2016).

The marine actinobacterial diversity has been mainly investigated by culture-dependent methods, and at least 66 actinobacterial genera have been cultured from different marine environments (Goodfellow and Fiedler, 2010; http://www. bacterio.net/). However, limited efforts have been devoted to exploring actinobacterial diversity and community compositions in the deep sea, particularly by using high-throughput sequencing approaches. A recent investigation using clone sequencing detected 9 actinobacterial genera from deep Arctic marine surface sediments (Zhang et al., 2014); and a targeted search for the marine actinomycetes Salinispora spp. using specific $16 \mathrm{~S}$ rRNA gene primers revealed the presence of this genus in deep marine sediments (3814-5699 $\mathrm{m}$ below water surface and $0-7 \mathrm{~m}$ below see floor [mbsf]) from the Canary Basin and South Pacific Gyre (Prieto-Davó et al., 2013). Data from previous studies on deep-sea microbial diversity showed that the relative abundance of actinobacteria in the sediments were $0.1-3.0 \%$ in the Arctic Ocean (0.38-2.32 mbsf; Jorgensen et al., 2012), $0.7-2.4 \%$ in the Atlantic Ocean (0-0.02 mbsf; Schauer et al., 2010), and about $10.0 \%$ in the Pacific Ocean (0-350 mbsf; Inagaki et al., 2006). In the hydrothermal surface sediments, the relative abundance of actinobacteria was found to be about $5.0 \%$ at the Mid-Atlantic Ridge (López-García et al., 2003) and about 3.8\% in the Guaymas Basin of Pacific Ocean (Teske et al., 2002). The metatranscriptomes of anaerobic Peru Margin sediment from 5 to 159 mbsf also indicated relatively abundant gene expression from Actinobacteria (1.2-6.1\%; Orsi et al., 2013). As for planktonic actinobacteria in the ocean, it was shown that their global distribution changed along latitudinal gradients (Pommier et al., 2007); however, their composition in the brackish northern Baltic Sea was related to environmental gradients including total phosphorus (TP), dissolved organic carbon, chlorophyll a, and bacterial production (Holmfeldt et al., 2009). These findings suggest a biogeographic distribution of actinobacteria that is shaped by biogeochemical parameters such as dissolved organic carbon, TP, etc. However, little is known about the actinobacterial diversity and biogeography in deep-sea habitats.

The Southwest Indian Ridge (SWIR) is one of the slowest spreading ocean ridges and has diverse geographic environments including an unexpected high frequency of hydrothermal vents and plumes (German et al., 1998; Tao et al., 2012, 2014). Hydrothermal systems are enriched with a variety of chemical substances (such as manganese $[\mathrm{Mn}]$, iron $[\mathrm{Fe}]$, methane $\left[\mathrm{CH}_{4}\right]$,

Abbreviations: NO-N, Nitrate Nitrogen; S, Sulphur; SWIR, Southwest Indian Ridge; TN, Total Nitrogen; TOC, Total Organic Carbon; TP, Total Phosphorus. hydrogen gas $\left[\mathrm{H}_{2}\right]$, reduced sulfur compounds, and polycyclic aromatic hydrocarbons [PAHs]) and form dynamic habitats with steep thermal and chemical gradients that may influence the microbial structure (Jannasch and Mottl, 1985; Baker et al., 1995; Simoneit and Fetzer, 1996). Due to its remote location, however, the SWIR is not readily accessible to investigate (Tao et al., 2012). Recently, a clone library study revealed that Thaumarchaeota, Acidobacteria, Actinobacteria, Bacteroidetes, and Proteobacteria dominated the archaeal and bacterial communities in a semiconsolidated carbonate sample of the SWIR and also suggested that Alphaproteobacteria and Thaumarchaeota potentially participated in sulfur (S) and nitrogen cycles in this environment (Li et al., 2014). Supporting this, another study demonstrated that Alphaproteobacteria, Gammaproteobacteria, Deltaproteobacteria, Firmicutes, Nitrospirae, and archaea might participate in the $S$ cycle in two low-temperature hydrothermal deposits at the SWIR (Cao et al., 2014). Nevertheless, it remains unclear about the abundance and composition of actinobacteria at the SWIR and the biogeochemical processes that they are involved in.

Besides the well-known ability of actinobacteria to produce diverse bioactive compounds, they also produce various extracellular hydrolytic enzymes, which have important ecological roles and potential biotechnological applications (Peczynska-Czoch and Mordarski, 1988). These enzymes are widely reported among soil actinobacteria and have been shown to participate in the decomposition of recalcitrant organic carbons such as polysaccharides (Manucharova, 2009). Moreover, members of the actinobacteria have also been reported as highly efficient $\mathrm{PAH}$ degraders in PAH-contaminated soils (Uyttebroek et al., 2006; García-Díaz et al., 2013). Cellulose, chitin, and pectin are the main components of eukaryotic cell walls, and thus are abundant and widely distributed in marine environments, serving as important sources of organic matter. Many of the actinobacteria isolated from coastal and shallow marine sediments are capable of producing cellulase, chitinase, and pectinase (Veiga et al., 1983; Augustine et al., 2013). However, there are few reports corresponding to such capabilities of deep-sea actinobacteria. PAHs are the main components of petroleum and are introduced into the marine environment by oil spill, river import, natural seepage, hydrothermal activity, and even air current transfer (Latimer and Zheng, 2003). PAHs are persistent organic pollutants that tend to accumulate in marine sediments and have even been reported to be widespread in the deep Arctic Ocean and Pacific Ocean (Simoneit and Fetzer, 1996; Dong et al., 2015). A recent study indicated that hydrocarbon-degrading actinobacteria, notably Dietzia, were abundant in the Arctic deep-sea sediments (0-0.5 mbsf) and were likely to play an important role in $\mathrm{PAH}$ degradation in situ (Dong et al., 2015).

In this study, we explored the diversity of actinobacteria at the SWIR using 16S rRNA gene pyrosequencing and culturedependent methods. We determined how the actinobacterial community from different sampling sites varied in composition and identified the environmental factors that contributed to the distribution of actinobacteria. The degradation capacity of diverse actinobacterial isolates toward recalcitrant organic 
substances was also evaluated, which might help to uncover their ecological functions and biotechnological applications. Our results provide new insights into the actinobacterial community structure at the SWIR and contribute to the understanding of the underlying mechanisms behind actinobacterial distribution in the deep ocean.

\section{MATERIALS AND METHODS}

\section{Sample Collection and Physicochemical Analysis}

Eight surface sediment samples (M1-M8) and a bottom water sample (M9) were collected along the SWIR at depths ranging from 1662 to $4000 \mathrm{~m}$ during the DY115-21 and DY115-22 cruises of the DaYang YiHao research vessel in January 2010, March 2010, and January 2011 (Figure 1, Table 1). Samples M8 and M9 were collected from the first discovered active hydrothermal field at the SWIR (Tao et al., 2012). A television multi-core sampler $(\Phi 10 \times 60 \mathrm{~cm})$ was deployed to collect surface sediment samples and a rosette water sampler equipped with 10-1 Niskin bottles and a CTD unit was used to collect the water sample. The sediment samples (0-0.2 mbsf) were transferred from the cores into sterile 200-ml plastic boxes using sterile scoops. Water for physicochemical analysis was collected in a sterile 1-1 glass bottle. Microbial cells were collected from 501 of water by a tangential flow filtration device (Millipore, Bedford, MA, USA) and further concentrated by subsequent filtration onto two polycarbonate filters (diameter $47 \mathrm{~mm}$, pore size $0.1 \mu \mathrm{m}$, Millipore) in the onboard laboratory. All samples were frozen at $-20^{\circ} \mathrm{C}$ until further processing in the laboratory.

Sample geochemical analyses were conducted at the Analysis Center of Tsinghua University. The samples were mixed with distilled water without $\mathrm{CO}_{2}$ (Millipore) at a 1:2.5 ratio, and the electric conductance and $\mathrm{pH}$ of the mixtures were determined using a $\mathrm{pH} /$ conductivity meter ( $\mathrm{HACH}$ Sension 156). The concentrations of total organic carbon (TOC) and total nitrogen (TN) were measured using the combustion method with the Elemental Analyzer (Euroea, Eurouector, Italy). Major elements $\mathrm{Mg}, \mathrm{S}, \mathrm{Ca}, \mathrm{Mn}$, and Fe were analyzed using inductively coupled plasma atomic emission spectroscopy (ICP-AES) (VISTA-MPX, VARIN, USA). The concentration of TP was determined using the modified Murphy Riley method (Carter and Gregorich, 2008). Nitrate nitrogen (NO-N) was quantified using the automated spectrophotometric method (Carter and Gregorich, 2008). The longitude, latitude, depth, and temperature were recorded by the research vessel. Detailed information of the samples is provided in Table 1. The map of sampling sites was drawn using the Generic Mapping Tools (Wessel and Smith, 1998) (http://gmt.soest.hawaii.edu/). Mercator projection and NUVEL-1A plate boundaries (http://jules.unavco.org/GMT/) were used for plotting.

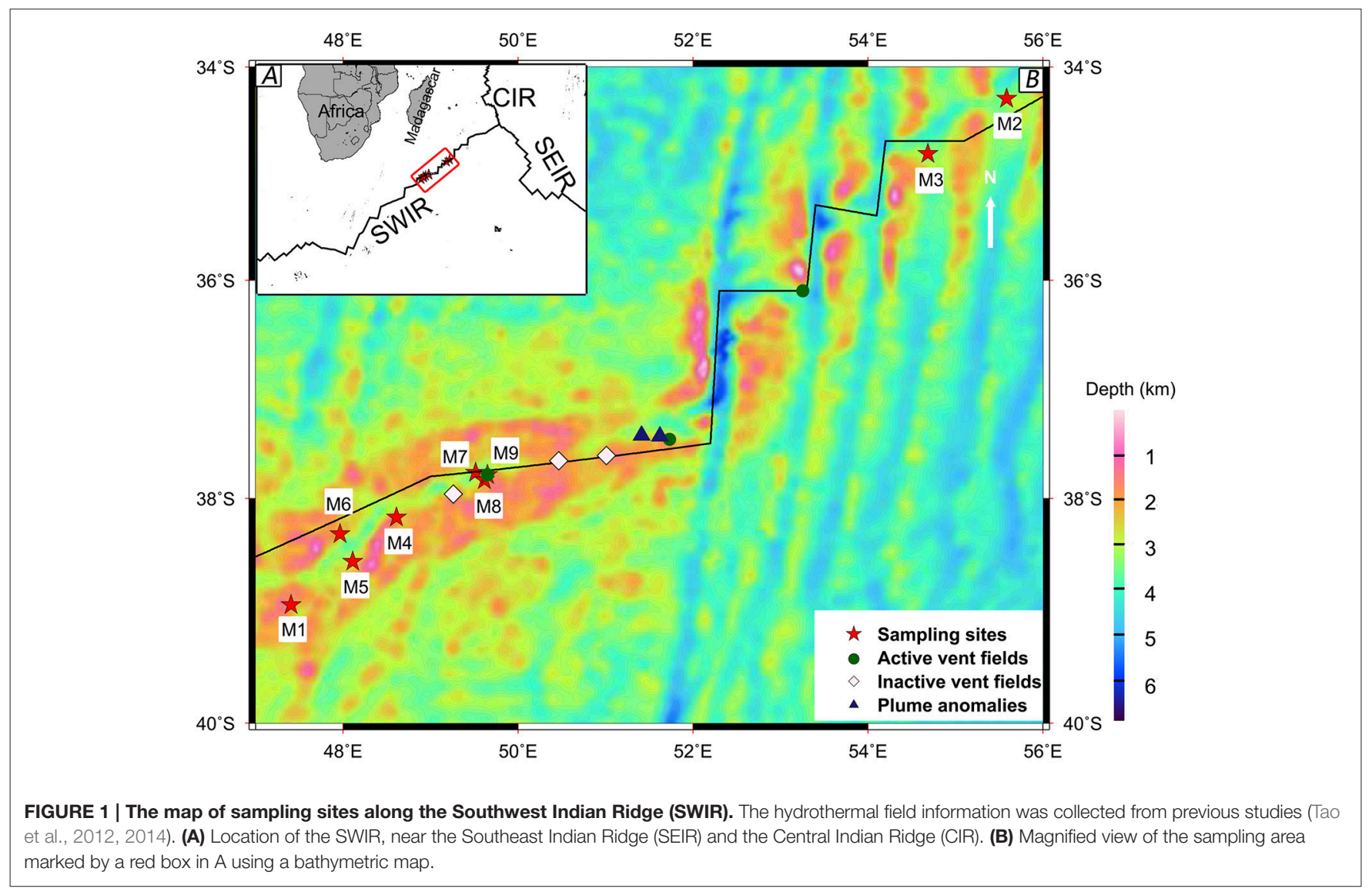




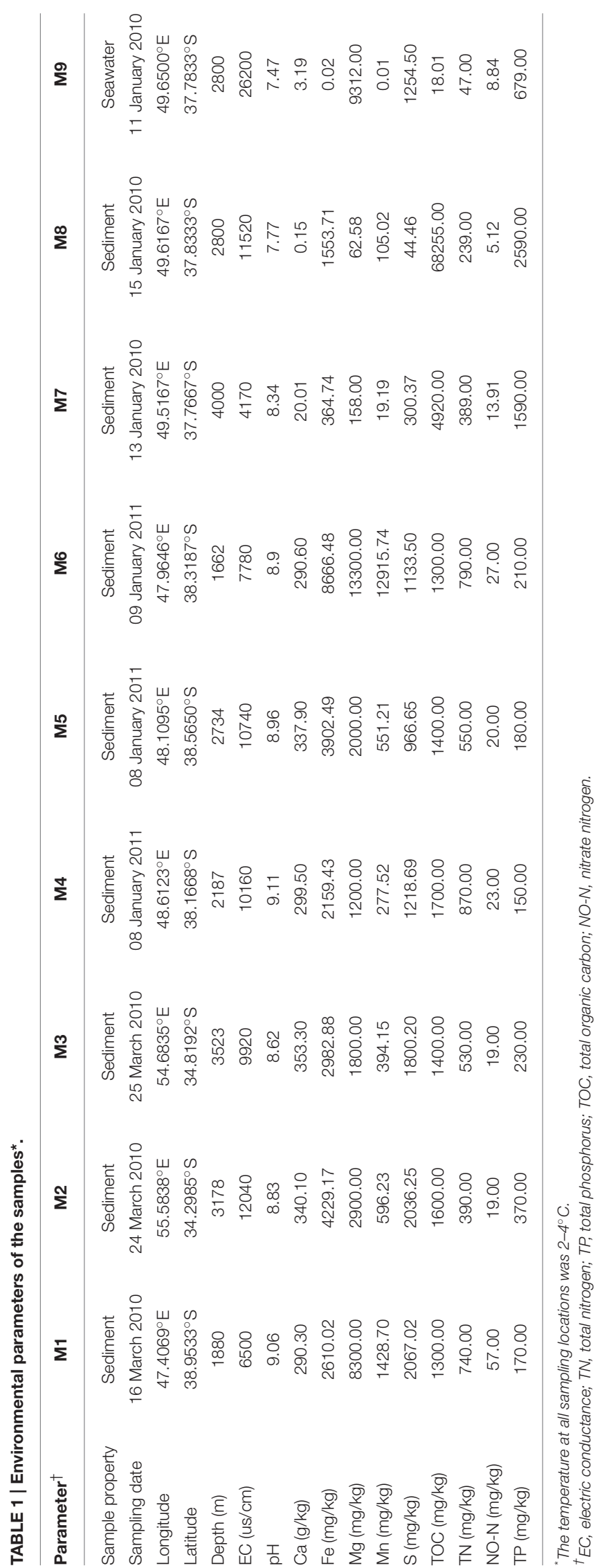

\section{DNA Extraction, PCR Amplification and Pyrosequencing of the 16S rRNA Gene}

Filters used to collect cells from the water samples were smashed in $20 \mathrm{ml}$ phosphate buffered solution in an ice bath using the Tissue Tearor (Model: 985370-395, Biospec Products, INC). A sample of sediment (5 $\mathrm{g}$ [wet weight]) or filter homogenate (5 $\mathrm{ml}$ ) was subjected to DNA extraction using the high-salt-SDSheat method (Zhou et al., 1996), with a modification that the mixture of sample and extraction buffer was frozen in liquid nitrogen and thawed in a $65^{\circ} \mathrm{C}$ water bath for three cycles and then cooled down to $37^{\circ} \mathrm{C}$ before proteinase $\mathrm{K}$ was added. For each sample, three replicates of DNA extracts were obtained and pooled together for the subsequent PCR amplication and pyrosequencing.

Due to the low coverage and relatively high false positive rate of the reported Actinobacteria-specific 16S rRNA gene primers (Stach et al., 2003b; Schäfer et al., 2010) and in order to investigate the actinobacterial relative abundance among the prokaryotic community, a pair of universal 16S rRNA gene primers was used in the present study. The total DNA was amplified in triplicate by PCR for pyrosequencing, using the primers U789F ( $5^{\prime}$-TAGATACCCSSGTAGTCC-3') and U1068R (5'-CTGACGRCRGCCATGC-3'; Baker et al., 2003; Lee et al., 2010) with 8-nucleotide barcodes. These primers target the V5V6 region on the 16S rRNA gene and cover about 93.0-96.0\% of bacteria and archaea (Klindworth et al., 2012). PCR was performed in triplicate in $50-\mu 1$ reaction system containing $5 \mathrm{U}$ of $P f u$ DNA polymerase, $1 \times P f u$ reaction buffer, $0.2 \mathrm{mM}$ of dNTPs (TaKaRa, Japan), $0.4 \mu \mathrm{M}$ of each barcoded primers, and $100 \mathrm{ng}$ of genomic DNA template. The amplification was conducted under the following conditions: initial denaturation at $94^{\circ} \mathrm{C}$ for $5 \mathrm{~min} ; 26$ cycles of denaturation at $94^{\circ} \mathrm{C}$ for $30 \mathrm{~s}$, annealing at $53^{\circ} \mathrm{C}$ for $30 \mathrm{~s}$ and extension at $72^{\circ} \mathrm{C}$ for $45 \mathrm{~s}$; and a final extension at $72^{\circ} \mathrm{C}$ for $6 \mathrm{~min}$ (Lee et al., 2010). The triplicate PCR products were pooled and purified using the TaKaRa Agarose Gel DNA Purification Kit (Takara, Japan). The amplicons from nine samples were quantified by Qubit dsDNA HS Assay Kit (Life Technologies, Eugene, Oregon, USA) on the Qubit 2.0 Fluorometer (Invitrogen, Carlsbad, CA, USA) and then mixed in equal amounts. The prepared DNAs were transformed into single-stranded template DNA (sstDNA) libraries by using the GS DNA Library Preparation Kit (Roche Applied Science). The sstDNA libraries were clonally amplified in a bead-immobilized form by using the GS emPCR Kit (Roche Applied Science) and then sequenced on the 454 Genome Sequencer GS FLX+ Titanium Platform (Roche Applied Science) at the Chinese National Human Genome Center, Shanghai, China.

\section{Pyrosequencing Data Processing and Statistical Analyses}

Pyrosequencing data were processed using Quantitative Insights Into Microbial Ecology (QIIME 1.7; Caporaso et al., 2010b). Sequences that contained ambiguous bases or were shorter than $150 \mathrm{bp}$ in length were discarded; only those with complete barcodes that were $100 \%$ identical to the expected barcodes, no more than three mismatches in the primer sequences (Huse 
et al., 2007), and an average quality score $>20$ were included in further analyses. Prior to the analysis, chimeric sequences were detected and excluded from the de-noised sequences using the QIIME implementation of the ChimeraSlayer algorithm (DeSantis et al., 2006; Haas et al., 2011). The high quality sequences were deposited in the NCBI database under accession number SRP046759. Uclust was used to identify phylotypes and assign sequences to operational taxonomic units (OTUs) at a distance cutoff of 0.03 (Edgar, 2010). The cluster seeds of OTUs were chosen as the representative sequences and aligned using PyNAST (Caporaso et al., 2010a) with the greengenes core set (DeSantis et al., 2006) as the template. The phylogenetic tree of the representative sequences was constructed using FastTree (Price et al., 2010). The software RDP classifier (Wang et al., 2007) was used to assign sequences to phylogenetic taxa based on the Ribosomal Database Project (Cole et al., 2013) under the condition of a bootstrap cutoff of 50\%. Actinobacterial reads unclassified at the family level were further annotated by online SINA 1.2.11 (Pruesse et al., 2012) based on the SILVA SSU Ref NR 99123.1 database. The alpha_diversity.py QIIME script was also used to calculate Shannon diversity estimators and Simpson's diversity index after rarefying reads to an even depth $(n=108$ reads) across samples.

The dissimilarity of phylogenetic diversity among the actinobacterial communities was measured by a weighted UniFrac distance matrix (Hamady et al., 2010). To correct the sampling error, the samples were rarefied to the minimal number of sequences for actinobacterial community. Dissimilarity matrices for geochemical characteristics were calculated using Euclidean distances, after standardizing the data to $Z$-score to make them comparable. A geographic distance matrix was calculated using the Vincenty formula and ln transformed for the correlation analysis as suggested by Martiny et al. (2011; Table S1). The dissimilarities of actinobacterial community compositions and environmental variables among samples were evaluated using the principal coordinate analysis (PCoA) method in QIIME, with weighted UniFrac and Euclidean distances, respectively. The Mantel test was used to assess the correlations between the actinobacterial community dissimilarity and environmental variables by 99,999 permutations in QIIME. Detrended correspondence analysis (Hill and Gauch, 1980), canonical correspondence analysis (Ter Braak, 1986), and partial canonical correspondence analysis (Borcard et al., 1992) were also performed to compute the correlations between the community structure and environmental variables in $\mathrm{R}$ version 3.1.0 ( $\mathrm{R}$ Core Team, 2014) using the functions in the Vegan package (Oksanen et al., 2013). Environmental variables with variance inflation factors over 20 , such as $\mathrm{Ca}$ and $\mathrm{Mn}$, were removed from the canonical correspondence analysis in order to exclude multicollinearity in the model (Yang et al., 2014).

\section{Selective Isolation of Actinobacteria}

The samples were processed using the following three methods.

(i) Ultrasonication/dilution (Qiu et al., 2008). One gram of sediment or $1 \mathrm{ml}$ of filter homogenate were added to $4 \mathrm{ml}$ of sterile artificial seawater (distilled water containing $3.3 \%$ sea salts), followed by shaking for $2 \mathrm{~h}$ at $28^{\circ} \mathrm{C}$ and $180 \mathrm{rpm}$ and processing in a water bath sonicator (model KQ-100DB, $40 \mathrm{kHz}, 100 \mathrm{~W}$; Kunshan Ultrasonic instruments Co., Ltd., Kunshan, China) for $2 \mathrm{~min}$ at $30^{\circ} \mathrm{C}$. The resulting samples were further diluted $(1: 1)$ with sterile artificial seawater.

(ii) Dispersion and differential centrifugation technique (Hopkins et al., 1991). One gram of sediment or $1 \mathrm{ml}$ of filter homogenate were blended with $5 \mathrm{ml} 0.1 \%(\mathrm{w} / \mathrm{v})$ sodium cholate, $5 \mathrm{ml}$ chelating resin $\left(\mathrm{Na}^{+}\right.$, Sigma), and approximately 10 glass beads, shaken for $2 \mathrm{~h}$ at $10^{\circ} \mathrm{C}$, and centrifuged at $500 \mathrm{~g}$ for $2 \mathrm{~min}$ to get the supernatant. The residue was resuspended in $5 \mathrm{ml}$ Tris buffer ( $\mathrm{pH}$ 7.4), shaken for $1 \mathrm{~h}$ at $10^{\circ} \mathrm{C}$, and centrifuged at $500 \mathrm{~g}$ for $1 \mathrm{~min}$ to get the supernatant. The two supernatants were pooled together as supernatant 1 . The above residue was resuspended in $5 \mathrm{ml}$ sodium cholate and processed in an ultrasonic bath for $1 \mathrm{~min}$, mixed with $5 \mathrm{ml}$ sodium cholate and shaken for $1 \mathrm{~h}$ at $10^{\circ} \mathrm{C}$, and then centrifuged at $500 \mathrm{~g}$ for $1 \mathrm{~min}$ to get supernatant 2. The resulting residue was resuspended in $10 \mathrm{ml}$ sterile distilled water, shaken for $1 \mathrm{~h}$ at $10^{\circ} \mathrm{C}$, and centrifuged at $500 \mathrm{~g}$ for $2 \mathrm{~min}$ to get supernatant 3 . The three supernatants of each sample were combined and centrifuged at $5000 \mathrm{~g}$ for $20 \mathrm{~min}$, and then the residue was resuspended in $1 \mathrm{ml}$ sterile artificial seawater for subsequent inoculation.

(iii) Enrichment/dilution. The ultrasonication/dilution sample was inoculated (1:10) in duplicate into SMP (Jensen et al., 2005) and M5 (Zhang et al., 2006) media without agar in 15$\mathrm{ml}$ centrifuge tubes, followed by incubation for 8 weeks at $16^{\circ} \mathrm{C}$ with the addition of fresh antibiotics $\left(50 \mathrm{mg} \mathrm{l}^{-1}\right.$ each of nalidixic acid and cycloheximide) every 2 weeks.

The pretreated samples were then diluted by 10 and 100 in sterile artificial seawater. Amounts of $100 \mu \mathrm{l}$ of each of the resulting dilutions were inoculated in quadruplicate onto the surface of the following selective agar media: AMM, SMP, SNC, and SRC (Jensen et al., 2005), 1/10 AMM, ISP 2 (modified with $0.2 \% \mathrm{CaCO}_{3}$ ), ISP 3 (Shirling and Gottlieb, 1966), and M5. All media were prepared with either natural seawater or artificial seawater and supplemented with $0.1 \%(\mathrm{v} / \mathrm{v})$ vitamin solution (Janssen et al., 1997), 0.1\% (v/v) trace salt solution (Shirling and Gottlieb, 1966), and $50 \mathrm{mg} \mathrm{l}^{-1}$ each of nalidixic acid and the anti-fungal agent cycloheximide or nystatin. The initial $\mathrm{pH}$ of each medium was adjusted to 7.2. The quadruplicate plates were divided into two sets and incubated respectively at 28 and $10^{\circ} \mathrm{C}$ for $2-15$ weeks. The plates were monitored every week and almost all growing colonies were transferred onto new AMM plates until pure cultures were obtained. The pure isolates were cryopreserved in $20 \%$ glycerol at $-80^{\circ} \mathrm{C}$.

\section{S rRNA Gene Sequencing of the Isolates and Phylogenetic Analysis}

Genomic DNA extraction from the isolates was performed as previously described (Chun and Goodfellow, 1995). Nearly complete 16S rRNA genes were PCR amplified using the universal primers $27 \mathrm{f}$ and $1492 \mathrm{r}$ (Lane, 1991). Reaction products were checked, purified, and directly sequenced using the 
previously described method (Guo et al., 2008). Nearly fulllength 16S rRNA gene sequences were obtained and edited with MEGA 5.20 (Tamura et al., 2011). The nearest related taxa were retrieved from the GenBank non-redundant database using a BLASTN search (http://www.ncbi.nlm.nih.gov/). Phylogenetic analysis of the isolates was conducted with MEGA 5.20. The phylogenetic tree was constructed using the maximum likelihood (ML) algorithm (Felsenstein, 1981) and the tree topology was evaluated by bootstrap analysis (Felsenstein, 1985) based on 1000 resamplings. The phylogenetic relationships of the isolates and actinobacterial sequences from the pyrosequencing data set were also analyzed. The alignment of all the isolate sequences and representative sequences of actinobacterial OTUs was performed using SINA (SILVA Incremental Aligner) web-based tool (Pruesse et al., 2012). ML phylogenetic tree reconstruction was performed with RAxML version 7.3.0 (Felsenstein, 1981; Stamatakis, 2006) with 100 rapid bootstrap inferences. The jModeltest 2.1 (Darriba et al., 2012) was used to select the bestfit substitution model in the above phylogenetic analyses, which was General Time Reversible model with Gamma distribution and Invariable sites $(\mathrm{GTR}+\mathrm{G}+\mathrm{I})$. Phylogenetic trees were edited with MEGA 5.20 (Tamura et al., 2011).

The 16S rRNA gene sequences of the actinobacterial isolates were deposited in the GenBank database with accession numbers KM507587-KM507721, HQ622494-HQ622502, HQ622504HQ622509, HQ622514-HQ622528, HQ622530-HQ622532, JF346424-JF346428, JF346418, JF346420, and JF346422.

\section{Biodegradation of Recalcitrant Organic Matter}

All actinobacterial isolates were qualitatively screened for their activity in the degradation of cellulose, chitin, pectin, fluoranthene, and phenanthrene using the previously described media and methods with modifications (Kiyohara et al., 1982; Veiga et al., 1983; Augustine et al., 2013). Briefly, each actinobacterial strain was spot inoculated in triplicate on nutrient agar containing sodium carboxymethyl cellulose (1\%), colloidal chitin $(0.2 \%)$, pectin $(0.5 \%)$, fluoranthene $\left(10 \mathrm{mg} \mathrm{l}^{-1}\right)$, and phenanthrene $\left(10 \mathrm{mg}^{-1}\right)$, respectively. Plates were incubated for $3-15$ days at $28^{\circ} \mathrm{C}$, and then colonies with transparent zones were considered as recalcitrant organic matter-degrading isolates. The cellulose and pectin plates were stained for $10 \mathrm{~min}$ with $0.5 \%$ congo red and then bleached for 10-20 min with $1 \mathrm{M} \mathrm{NaCl}$ before the observation of transparent zones.

\section{RESULTS}

\section{Environmental Characteristics of the Study Sites}

Eleven physicochemical and three geographic parameters of the samples were obtained (Table 1). PCoA analysis of the $Z$-scored physicochemical factors showed that samples collected from different sites varied from one another, and samples M8 and M9, which were collected from a hydrothermal field, were distinct from the others (Figure 2). The pairwise geographic distance

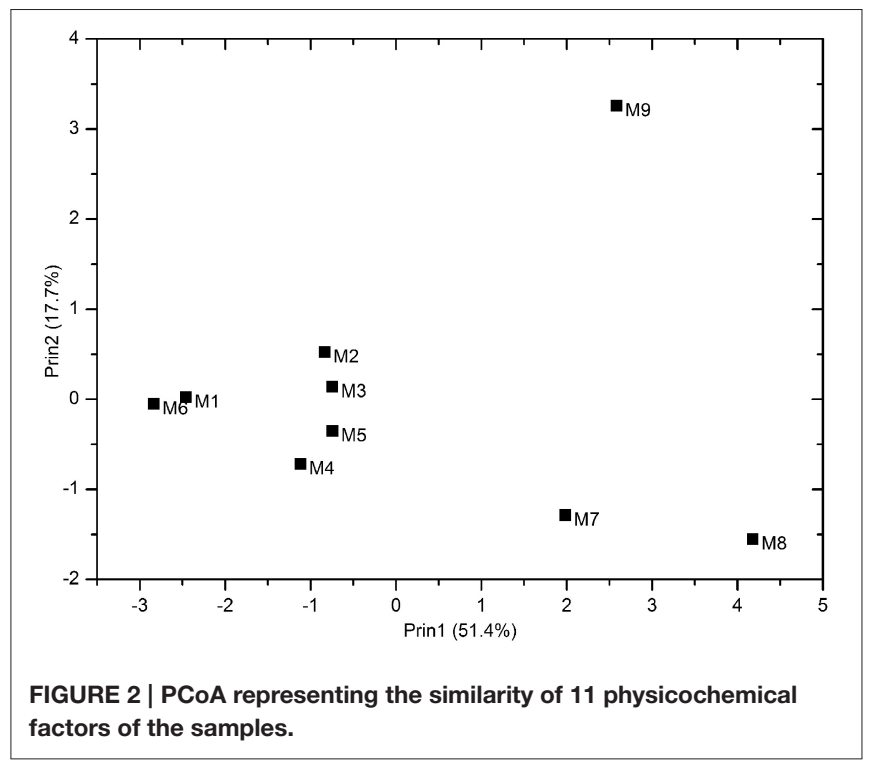

between the sampling sites ranged from 5.2 (between M8 and M9) to $964.9 \mathrm{~km}$ (between M1 and M2; Figure 1; Table S1).

\section{Community Compositions of Actinobacteria}

A total of 72,889 quality-filtered $16 \mathrm{~S}$ rRNA gene sequences with an average read length of approximately $250 \mathrm{bp}$ were obtained for further analysis, with 49,717 sequences belonging to bacteria and 23,057 to archaea. Altogether, 28 bacterial and two archaeal phyla were recovered. Among them, Proteobacteria, Thaumarchaeota, Actinobacteria, Planctomycetes, and Firmicutes were the most abundant (relative abundance $>1 \%$ in each sample). The phylum Actinobacteria represented $4.5 \%$ (3245 sequences) of the total reads and $1.2-9.1 \%$ of the reads among the samples. The actinobacterial sequences could be divided into 764 OTUs using Uclust at a distance of 0.03 and each sample contained 58-219 OTUs. None of the actinobacterial OTUs were distributed in all samples. The actinobacterial $\alpha$-diversity, based on the Shannon and Simpson diversity indexes, was not significantly different between the samples (Table 2).

Five known actinobacterial classes (Acidimicrobiia, Actinobacteria, Coriobacteriia, Rubrobacteria, and Thermoleophilia) were detected, of which Actinobacteria and Acidimicrobiia were the most abundant (Figure S1). A total of 300 OTUs spanning nearly half $(47.7 \%)$ of the actinobacterial reads could not be assigned to any known classes within the taxonomic framework of the phylum Actinobacteria when using the RDP classifier. These OTUs accounted for $42.0-74.1 \%$ of the actinobacterial reads in samples M1-M7 while only $5.8 \%$ in M8 and $6.6 \%$ in M9.

At the rank of order, $63.2 \%$ (8.4-93.2\% among the samples) of the actinobacterial reads could not be classified, however, 17 known actinobacterial orders were detected (Figure 3). Acidimicrobiales (2.1-27.0\%) and Corynebacteriales (0.3-40.9\%) were the most widely distributed, present in all samples, followed by Micrococcales (0.6-11.5\%) and Propionibacteriales (0.7-7.0\%), 
TABLE 2 | The number of OTUs and the estimators of richness and diversity at 0.03 dissimilarity.

\begin{tabular}{|c|c|c|c|c|c|c|c|}
\hline Sample ID & Total reads & Total OTUs & Total coverage & Actinobacterial reads (\%) & Actinobacterial OTUs (\%) & Shannon* & Simpson* \\
\hline M1 & 7436 & 3548 & 0.65 & $293(3.9)$ & $130(3.7)$ & 5.34 & 0.97 \\
\hline M2 & 8079 & 3955 & 0.64 & $108(1.3)$ & $64(1.6)$ & 5.17 & 0.96 \\
\hline M3 & 7500 & 3559 & 0.65 & $136(1.8)$ & $65(1.8)$ & 5.13 & 0.95 \\
\hline M4 & 6442 & 3295 & 0.62 & $351(5.4)$ & $118(3.6)$ & 4.30 & 0.87 \\
\hline M5 & 11060 & 4794 & 0.68 & $774(7.0)$ & $193(4.0)$ & 4.51 & 0.93 \\
\hline M6 & 9807 & 3897 & 0.71 & $119(1.2)$ & $58(1.5)$ & 5.09 & 0.96 \\
\hline M7 & 6770 & 2848 & 0.68 & $617(9.1)$ & $171(6.0)$ & 4.90 & 0.95 \\
\hline M8 & 8826 & 3535 & 0.73 & 274 (3.1) & 72 (2.0) & 3.98 & 0.89 \\
\hline M9 & 6969 & 2493 & 0.74 & $573(8.2)$ & 219 (8.8) & 5.05 & 0.94 \\
\hline Total & 72889 & 23836 & 0.73 & 3245 (4.5) & 764 (3.2) & & \\
\hline
\end{tabular}

*Index for actinobacterial community.

present in eight samples except for M6. Streptomycetales occurred in samples M7-M9, accounting for almost half (49.0\%) of the reads in M9 but only 4.4 and 3.3\% in M7 and M8, respectively. In contrast to the non-hydrothermal field sediment samples M1-M7, where unclassified actinobacteria at the order rank accounted for more than $68.5 \%$, the hydrothermal field sediment sample M8 contained Corynebacteriales (40.9\%) as the most abundant order and had a much higher relative abundance of Acidimicrobiales, Micrococcales, Micromonosporales, Streptomycetales, and Pseudonocardiales. The hydrothermal field bottom water sample M9 contained the highest number (13) of known orders.

Only $28.5 \%$ of the reads could be further classified into the known families ( 28 in total), and the majority of unclassified reads at the family rank belonged to the order Acidimicrobiales. None of the known families were discovered in all samples and seven were present in only one of the samples (Figure S2). The families Acidimicrobiaceae, Iamiaceae, and Propionibacteriaceae were obtained from eight samples, followed by Micrococcaceae and Nocardiaceae from seven samples, and Microbacteriaceae and Tsukamurellaceae from six samples. These families were relatively abundant in the actinobacterial community ( $>1 \%$ of the total actinobacterial reads; Figure S2). All the Streptomycetales reads could be further classified into Streptomycetaceae, which was also abundant.

When looking at the genus level, at least 52 known genera were detected. Among them, 35 genera represented non-filamentous actinobacteria according to the previous descriptions of the genera (Goodfellow et al., 2012), accounting for nearly half of the total known actinobacterial reads. Six genera were found to be abundant (Figure 4), of which Iamia, Microbacterium, Propionibacterium, and Tsukamurella were reported to be nonfilamentous, while Gordonia and Streptomyces were filamentous (Goodfellow et al., 2012).

The actinobacterial sequences unclassified at the family level using the RDP classifier, belonging to 513 OTUs and accounting for $71.5 \%$ of actinobacterial reads, were further classified using SINA Alignment Service based on the SILVA database. Nearly half of these OTUs (241 OTUs) were classified as OM1 group of Acidimicrobiales, which is also an uncultured group

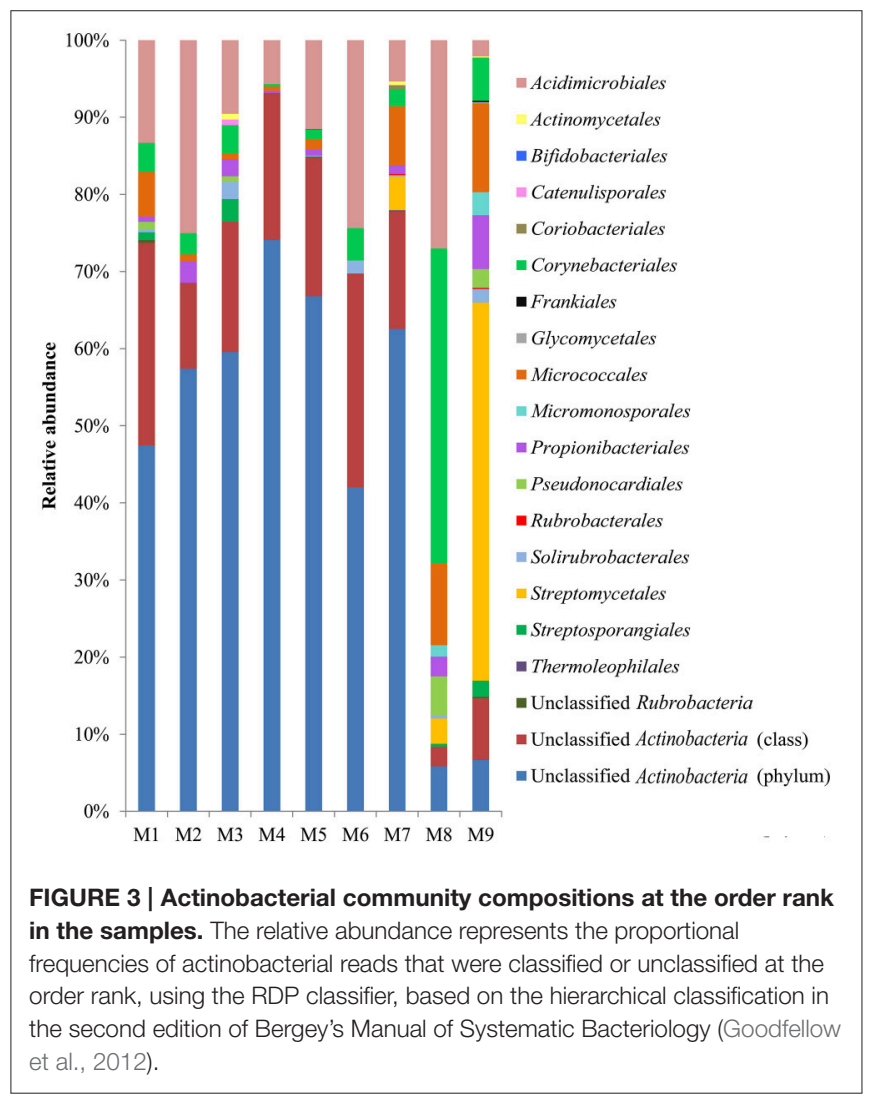

(Yilmaz et al., 2016), accounting for $81.3 \%$ of the unclassified reads. The identities to the reference OM1 sequences were 85.5-100.0\%. Most of the other OTUs (173 OTUs accounting for $10.3 \%$ of the unclassified reads) remained unclassified and showed 70.8-94.6\% identities to the unclassified sequences in the SILVA database. Only 99 OTUs could be further classified. Among them, 54 OTUs were classified to known or candidatus genera or families including Acidothermus, Arthrobacter, Brevibacterium, Candidatus Microthrix, Corynebacterium, Crossiella, Frankiaceae, Geodermatophilus, Jatrophihabitans, Mycobacterium, Pseudonocardiaceae, Rothia, Solirubrobacterales 


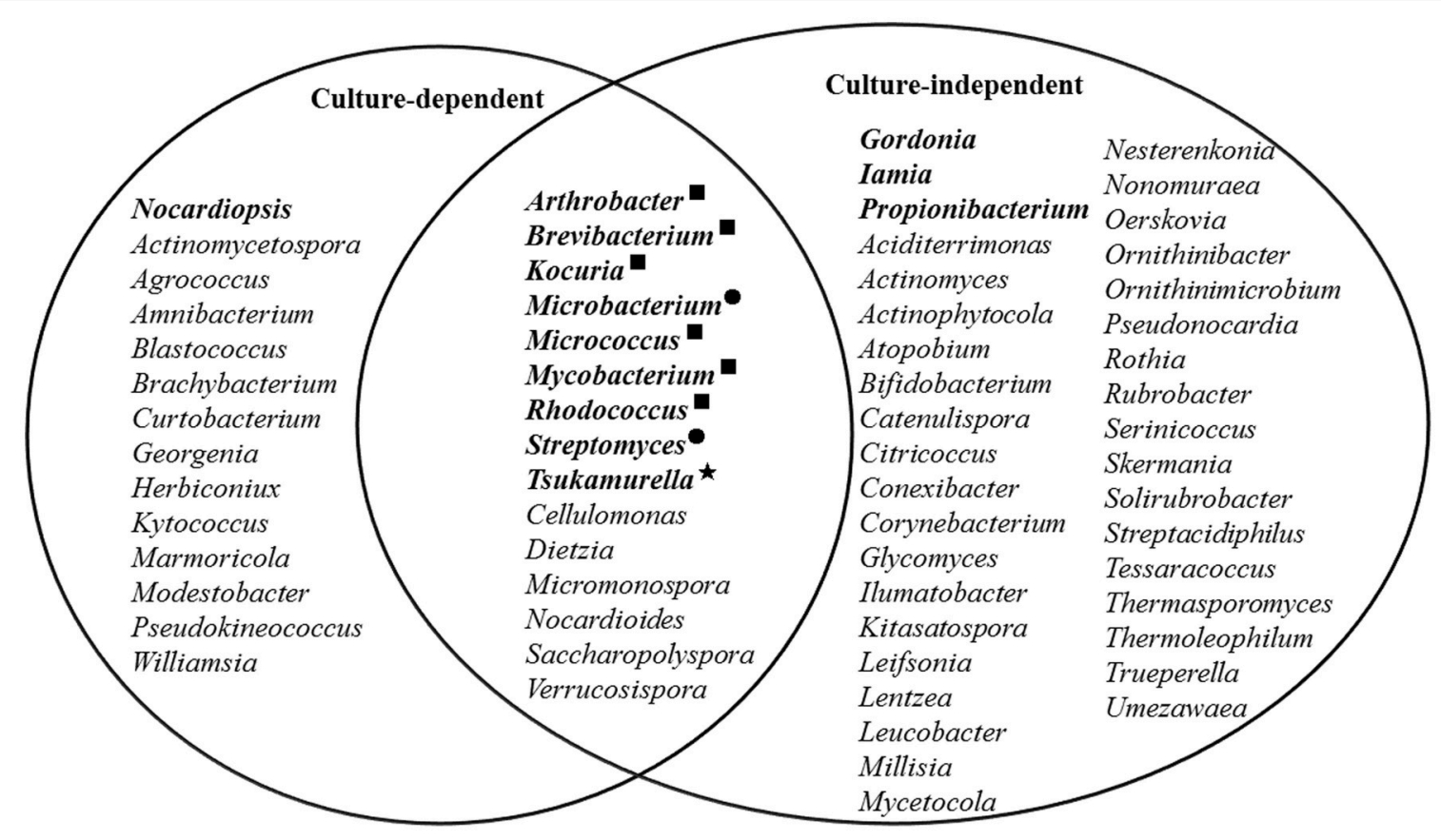

FIGURE 4 | Actinobacterial genera detected by culture-dependent and -independent methods. The most abundant genera are shown in bold, and the black dots, star, and squares indicate those that were abundant in both methods, pyrosequencing only, and cultivation only, respectively.

480-2, Solirubrobacterales Elev-16S-1332, Streptomyces, and Sva0996 marine group; 38 OTUs were classified to known or candidatus orders including Acidimicrobiales, Frankiales, Gaiellales, Micrococcales, PAUC43f marine benthic group, and Solirubrobacterales; and 7 OTUs were classified to known or candidatus classes of Actinobacteria, OPB41, TakashiAC-B11, and Thermoleophilia.

\section{Correlating Actinobacterial Community Compositions with Environmental Factors}

The diversity analysis showed that the relative abundance of actinobacterial taxa varied in different samples (Figure 3, Figures S1, S2). PCoA analysis at the 0.03 OTU level further confirmed obvious variations in the actinobacterial community among the samples (Figure S3), a result in line with that of physicochemical factors (Figure 2). Simple Mantel tests between the distance matrix of actinobacterial communities and distance matrices of environmental variables showed that the community structure of the samples was significantly correlated to $\mathrm{pH}$, TOC, TP, Ca and TN $(P<0.05$; Table 3$)$, where $\mathrm{pH}$ showed the highest correlation $(r=0.813, P=0.020)$. When considering only the non-hydrothermal field samples, the actinobacterial community structure was merely correlated with $\mathrm{Ca}$ and $\mathrm{pH}$ $(P<0.05)$. Canonical correspondence analysis, which was chosen as the appropriate mathematical model in consideration of the axis lengths in Detrended correspondence analysis (Lepš and Šmilauer, 2003), was also performed to identify the major environmental factors shaping the actinobacterial community structure. The result demonstrated a significant model $(P=$
TABLE 3 | Correlations between the actinobacterial community structure ( 0.03 OTU level) and environmental variables by Mantel tests.

\begin{tabular}{lcc}
\hline Factor & $\boldsymbol{r}$ & $\boldsymbol{P}$ \\
\hline pH & $\mathbf{0 . 8 1 3}$ & $\mathbf{0 . 0 2 0}$ \\
TOC & $\mathbf{0 . 6 4 0}$ & $\mathbf{0 . 0 2 7}$ \\
TP & $\mathbf{0 . 5 2 6}$ & $\mathbf{0 . 0 4 1}$ \\
Ca & $\mathbf{0 . 5 2 3}$ & $\mathbf{0 . 0 4 0}$ \\
TN & $\mathbf{0 . 4 8 7}$ & $\mathbf{0 . 0 2 2}$ \\
Ln_Distance & -0.167 & 0.726 \\
EC & 0.390 & 0.170 \\
Fe & 0.016 & 0.286 \\
Mg & -0.005 & 0.315 \\
Mn & -0.122 & 0.388 \\
S & 0.121 & 0.291 \\
NO-N & 0.140 & 0.240 \\
\hline
\end{tabular}

The significant correlations are shown in bold.

0.042) with seven environmental variables ( $\mathrm{pH}, \mathrm{TOC}, \mathrm{Fe}$, $\mathrm{Mg}, \mathrm{S}, \mathrm{TN}$, and TP), which explained $91.2 \%$ variance of the actinobacterial community compositions with 22.6 and $20.2 \%$ explained by the first and second axes, respectively (Figure 5). Among these seven variables, $\mathrm{pH}$ and TOC were the most important environmental factors. Geographic distance was not a significant factor because the $P$-values were $>0.05$ in both the Mantel test and ordination analysis.

The relative abundance of the phylum Actinobactreia showed a significantly negative correlation with $\mathrm{Fe}(r=-0.676, P=$ $0.045)$. The relationship between the relative abundance of the 


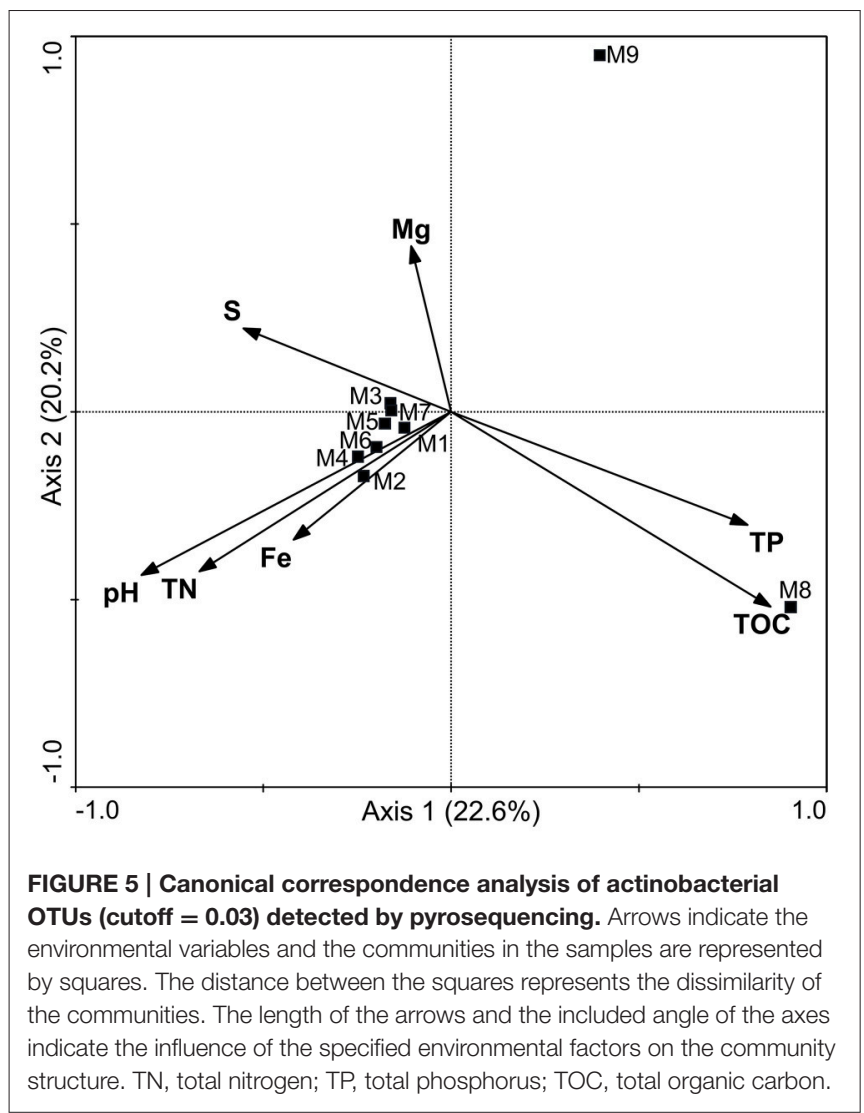

major groups of actinobacteria and environmental factors was further analyzed. The class Actinobactreia showed significant correlations with $\mathrm{Mn}(r=-0.849, P=0.004), \mathrm{pH}(r=-0.715$, $P=0.004)$, NO-N $(r=0.754, P=0.019)$, Fe $(r=-0.724$, $P=0.027)$, and $\mathrm{Mg}(r=0.676, P=0.046)$. At the order rank, significant correlations were found between Corynebacteriales and TP $(r=0.838, P=0.005)$, Micrococcales and $\mathrm{Ca}(r=-0.920$, $P=0.000), \mathrm{pH}(r=-0859, P=0.003), \mathrm{TN}(r=-0.749$, $P=0.020)$, Fe $(r=-0.715, P=0.030)$, and TP $(r=$ $0.713, P=0.031)$, and between Propionibacteriales and electric conductance $(r=0.904, P=0.001)$, TN $(r=-0.862, P=0.003)$, and $\mathrm{pH}(r=-0.817, P=0.007)$. For the known actinobacterial families, only Micrococcaceae and Propionibacteriaceae showed negative correlations to $\mathrm{TN}$ and $\mathrm{pH}$ and a positive correlation to electric conductance (Figure S4). The results also indicated that unclassified Actinobacteria (phylum) positively correlated with $\mathrm{pH}$ and $\mathrm{TN}$, unclassified Actinobacteria (class) correlated with $\mathrm{TN}, \mathrm{NO}-\mathrm{N}$, and $\mathrm{pH}$, and unclassified Acidimicrobiales highly correlated with Fe (Figure S4). Some of the OTUs within these unclassified/uncultured groups were more influenced than others, including the OTUs detected in most of the samples. For instance, OTU00513 and OTU00620 showed significant correlations with $\mathrm{pH}(r=0.782, P=0.013 ; r=0.692, P=0.039)$ and TN ( $r=0.689, P=0.040 ; r=0.764, P=0.017)$, OTU00305 and OTU00066 significantly correlated to TN $(r=0.791$, $P=0.011 ; r=0.712, P=0.032)$, OTU00085 and OTU00624 correlated to NO-N $(r=0.771, P=0.015 ; r=0.721, P=0.028)$, and OTU00183 had a highly significant correlation with $\mathrm{Fe}(r=$ $0.854, P=0.003$ ). All the above mentioned OTUs were classified to Acidimicrobiales OM1 clade using the SILVA database.

Besides the geochemical parameters, correlations between the relative abundance of the phylum Actinobactreia and other bacterial and archaeal phyla present in the samples were also evaluated. The result showed a significant correlation between Actinobactreia and Chloroflexi $(r=0.678, P=0.045)$.

\section{Diversity of Culturable Actinobacteria}

To further investigate the diversity and potential functions of actinobacteria at the SWIR, the samples were subjected to isolation of actinobacterial strains using three pretreatments and eight selective media. A total of 176 actinobacterial strains were purified from the samples. Most of the strains were isolated from ISP 3 (62 strains) and AMM (46 strains) media. The 16S rRNA gene sequences of the isolates were affiliated with 29 genera, 18 families, and 9 orders within the Actinobacteria class, of which 15 genera, 13 families and 8 orders were also found in the pyrosequencing data set (Figures 4, 6). The isolates showed 97.3$100 \% 16$ S rRNA gene sequence similarities to the closest known actinobacterial species, with the most divergent isolate belonging to Nocardioides.

A total of $77.3 \%(136 / 176)$ of the isolates showed $\geq 97 \%$ 16S rRNA sequence similarities to the pyrosequencing reads, whereas only $10.3 \%(335 / 3245)$ of the in situ actinobacterial community were represented by the isolates when mapping the actinobacterial reads against the sequences of the isolates at the $97 \%$ similarity cutoff. The phylogenetic analysis on all the isolates and representative actinobacterial sequences from the pyrosequencing data set also supported the above results (Figure 7). Most of the isolates clustered closely with the environmental sequences, formed 8 of the 18 known orders detected in total. Nine known orders contained sequences from only the pyrosequencing but not the isolates, while the order Kineosporiales contained only the isolate sequences. On the other hand, most of the unclassified/uncultured pyrosequencing sequences formed independent clades that were distinguished from the isolates, notably the Acidimicrobiales OM1 clade which was also distinct from the clade of the order Acidimicrobiales and should probably be named as a new order. The phylogenetic tree also showed that there were 14 Acidimicrobiia clades and a number of unclassified actinobacterial sequences clustered with the OM1 clade, and there were at least three distinguished Actinobacteria clades (Actinobacteria clades 6-8) that might respectively represent new orders within the phylum Actinobacteria (Figure 7, Figures S5A-S5F).

Among the 15 genera that were present in both the pyrosequencing and cultural data sets, only three (Streptomyces, Tsukamurella, and Microbacterium) were abundant in pyrosequencing $(8.8,2.1$, and $1.5 \%$, respectively); and most of the cultured genera represented rare groups or were absent in pyrosequencing. None of the genera were recovered from all samples. The non-filamentous genera Kocuria (35 isolates) and Microbacterium (31 isolates), both belonging to the order Micrococcales, were the most abundant of the culturable genera. 


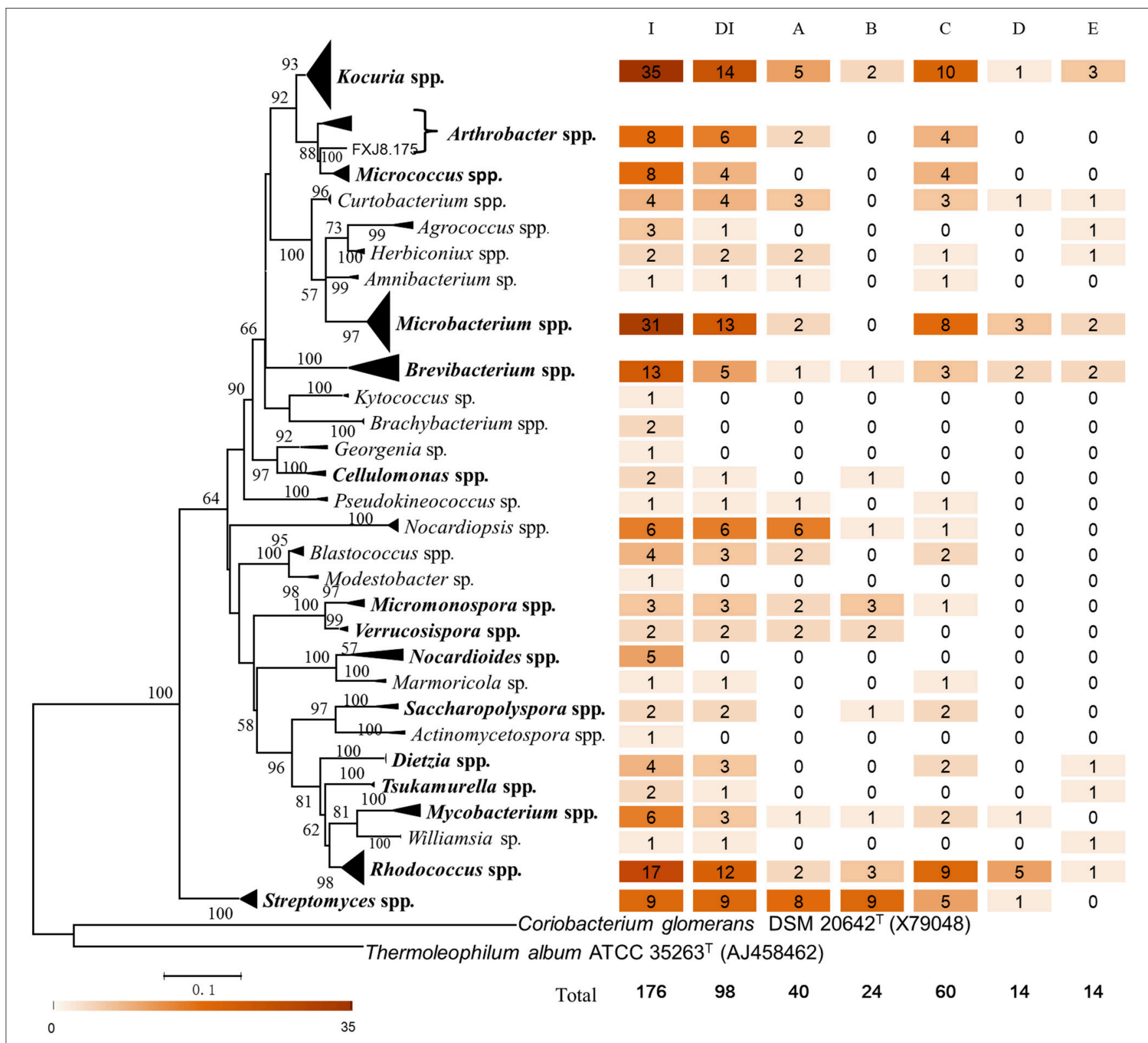

FIGURE 6 | Phylogenetic diversity, taxonomic affiliation and degradation capacity of culturable actinobacterial isolates. The maximum-likelihood tree was based on nearly full-length 16S rRNA gene sequences of the isolates and closely related type strains. The GTR+G+I evolutionary model was selected to construct the tree. Coriobacterium glomerans DSM 20642T and Thermoleophilum album ATCC 35263T were set as outgroups. Numbers at branch nodes are percentages of bootstrap replicates of 1000 resamplings (only values above $50 \%$ are shown). The bar represents 0.1 substitutions per nucleotide position. Genera that were also recovered in the pyrosequencing data set are in bold. Numbers following each genus indicate the number of isolates or degrading isolates. I, number of isolates; DI, number of degrading isolates; A, number of cellulose-degrading isolates; B, number of chitin-degrading isolates; C, number of pectin-degrading isolates; D, number of fluoranthene-degrading isolates; $\mathrm{E}$, number of phenanthrene-degrading isolates.

Microbacterium isolates were obtained from all samples except M1, while Kocuria isolates were from M1, M4, M6, and M9. The highest diversity of isolates was observed for the hydrothermal field bottom water sample M9 (13 genera), followed by sample M4 (12 genera); and the lowest diversity was observed for samples M3 and M7, each affiliated with only four genera (Table 4).

\section{Biodegradation Activity of Actinobacterial Isolates}

The majority of isolates (98 of 176) demonstrated activity in the degradation of refractory organics, i.e., cellulose (40 isolates, $22.7 \%$ ), chitin (24 isolates, $13.6 \%$ ), pectin (60 isolates, $34.1 \%$ ), fluoranthene (14 isolates, $8.0 \%$ ), and phenanthrene (14 isolates, 8.0\%; Figure 6). The degrading isolates spread across 23 


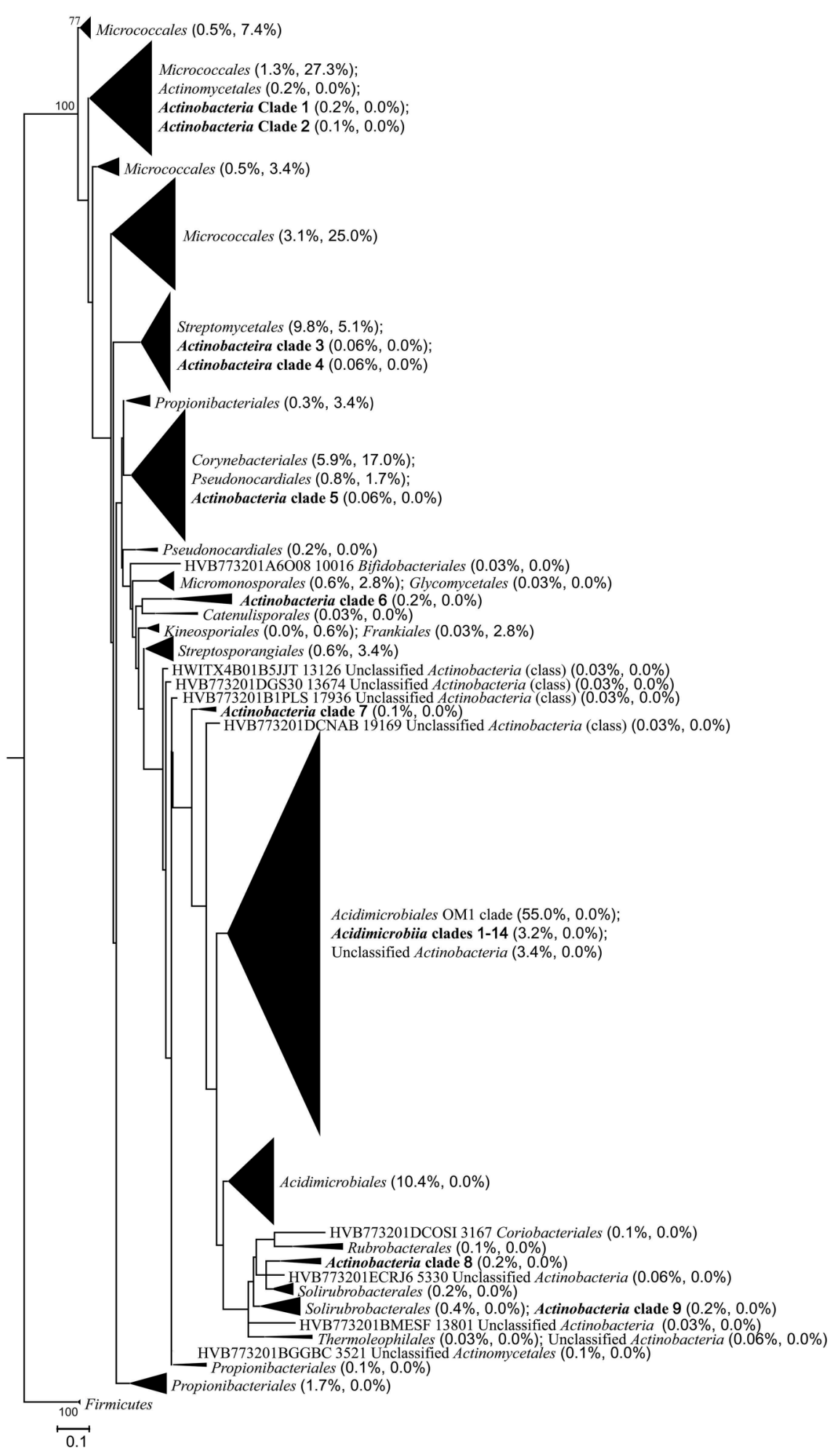

FIGURE 7 | Maximum-likelihood phylogenetic tree based on partial 16S rRNA gene sequences illustrating the relationships among all the isolates and representative actinobacterial sequences from the pyrosequencing data set. The tree was constructed using the GRT+G+I model. Firmicutes was set as the outgroup. Taxonomic assignments of the sequences were based on both the RDP and SILVA databases. The tree is displayed at order level. Numbers at branch nodes are percentages of bootstrap replicates of 100 resamplings (only values above $50 \%$ are shown). Numbers in the parentheses following each order or clade indicate the relative abundance of pyrosequencing reads and isolates, respectively. The bar represents 0.1 substitutions per nucleotide position. 
TABLE 4 | Numbers of isolates (and degrading isolates) at the genus level from different samples.

\begin{tabular}{|c|c|c|c|c|c|c|c|c|c|c|c|c|}
\hline Orders & Family & Genus & M1 & M2 & M3 & M4 & M5 & M6 & M7 & M8 & M9 & Total \\
\hline \multirow[t]{5}{*}{ Corynebacteriales } & Dietziaceae & Dietzia & 0 & 0 & $1(1)$ & 0 & 0 & 0 & $1(0)$ & 0 & $2(2)$ & $4(3)$ \\
\hline & Mycobacteriaceae & Mycobacterium & 0 & 0 & 0 & 0 & $3(2)$ & $1(0)$ & 0 & $1(1)$ & $1(0)$ & $6(3)$ \\
\hline & Nocardiaceae & Rhodococcus & 0 & $1(1)$ & 0 & $8(6)$ & 0 & 0 & $5(2)$ & $1(1)$ & $2(2)$ & $17(12)$ \\
\hline & Tsukamurellaceae & Tsukamurella & 0 & 0 & 0 & 0 & 0 & 0 & 0 & $1(1)$ & $1(0)$ & $2(1)$ \\
\hline & Nocardiaceae & Williamsia & 0 & 0 & 0 & 0 & $1(1)$ & 0 & 0 & 0 & 0 & $1(1)$ \\
\hline \multirow[t]{2}{*}{ Frankiales } & Geodermatophilaceae & Blastococcus & 0 & 0 & 0 & $2(1)$ & $1(1)$ & $1(1)$ & 0 & 0 & 0 & $4(3)$ \\
\hline & & Modestobacter & 0 & 0 & 0 & 0 & $1(0)$ & 0 & 0 & 0 & 0 & $1(0)$ \\
\hline Kineosporiales & Kineosporiaceae & Pseudokineococcus & 0 & 0 & 0 & $1(1)$ & 0 & 0 & 0 & 0 & 0 & $1(1)$ \\
\hline \multirow[t]{13}{*}{ Micrococcales } & Brevibacteriaceae & Brevibacterium & $2(2)$ & $1(1)$ & 0 & 0 & 0 & 0 & 0 & $4(2)$ & $6(0)$ & $13(5)$ \\
\hline & Bogoriellaceae & Georgenia & 0 & $1(0)$ & 0 & 0 & 0 & 0 & 0 & 0 & 0 & $1(0)$ \\
\hline & Cellulomonadaceae & Cellulomonas & 0 & 0 & 0 & 0 & $1(0)$ & 0 & 0 & 0 & $1(1)$ & $2(1)$ \\
\hline & Microbacteriaceae & Agrococcus & 0 & 0 & 0 & $1(1)$ & 0 & 0 & $2(0)$ & 0 & 0 & $3(1)$ \\
\hline & & Amnibacterium & 0 & 0 & 0 & $1(1)$ & 0 & 0 & 0 & 0 & 0 & $1(1)$ \\
\hline & & Curtobacterium & $1(1)$ & $1(1)$ & 0 & $1(1)$ & $1(1)$ & 0 & 0 & 0 & 0 & $4(4)$ \\
\hline & & Herbiconiux & 0 & $1(1)$ & 0 & 0 & $1(1)$ & 0 & 0 & 0 & 0 & $2(2)$ \\
\hline & & Microbacterium & 0 & $6(1)$ & $1(0)$ & $3(2)$ & $10(6)$ & $6(1)$ & $1(0)$ & $1(1)$ & $3(2)$ & $31(13)$ \\
\hline & Micrococcaceae & Arthrobacter & $1(1)$ & $1(1)$ & 0 & $2(2)$ & $4(2)$ & 0 & 0 & 0 & 0 & $8(6)$ \\
\hline & & Micrococcus & $3(1)$ & $1(1)$ & 0 & $1(0)$ & 0 & 0 & 0 & 0 & $3(2)$ & $8(4)$ \\
\hline & & Kocuria & $26(9)$ & 0 & 0 & $3(1)$ & 0 & $3(3)$ & 0 & 0 & $3(1)$ & $35(14)$ \\
\hline & Dermabacteraceae & Brachybacterium & 0 & $2(0)$ & 0 & 0 & 0 & 0 & 0 & 0 & 0 & $2(0)$ \\
\hline & Dermacoccaceae & Kytococcus & 0 & 0 & 0 & 0 & $1(0)$ & 0 & 0 & 0 & 0 & $1(0)$ \\
\hline \multirow[t]{2}{*}{ Micromonosporales } & Micromonosporaceae & Micromonospora & $2(2)$ & 0 & 0 & $1(1)$ & 0 & 0 & 0 & 0 & 0 & $3(3)$ \\
\hline & & Verrucosispora & 0 & 0 & 0 & 0 & 0 & 0 & 0 & 0 & $2(2)$ & $2(2)$ \\
\hline \multirow[t]{2}{*}{ Propionibacteriales } & Nocardioidaceae & Marmoricola & 0 & $1(1)$ & 0 & 0 & 0 & 0 & 0 & 0 & 0 & $1(1)$ \\
\hline & & Nocardioides & 0 & 0 & 0 & $1(0)$ & $4(0)$ & 0 & 0 & 0 & 0 & $5(0)$ \\
\hline Streptosporangiales & Nocardiopsaceae & Nocardiopsis & 0 & 0 & 0 & 0 & 0 & $1(1)$ & 0 & $2(2)$ & $3(3)$ & $6(6)$ \\
\hline \multirow[t]{2}{*}{ Pseudonocardiales } & Pseudonocardiaceae & Actinomycetospora & 0 & $1(0)$ & 0 & 0 & 0 & 0 & 0 & 0 & 0 & $1(0)$ \\
\hline & & Saccharopolyspora & 0 & 0 & $1(1)$ & 0 & 0 & 0 & 0 & 0 & $1(1)$ & $2(2)$ \\
\hline Streptomycetales & Streptomycetaceae & Streptomyces & $4(4)$ & 0 & $2(2)$ & 0 & 0 & 0 & 0 & $1(1)$ & $2(2)$ & $9(9)$ \\
\hline \multicolumn{2}{|c|}{ No. of isolates (degrading isolates) } & & $39(20)$ & $17(8)$ & $5(4)$ & $25(17)$ & $28(14)$ & $12(6)$ & $9(2)$ & $11(9)$ & $30(18)$ & $176(98)$ \\
\hline \multicolumn{2}{|c|}{ No. of genera (degrading genera) } & & $7(7)$ & $11(8)$ & $4(3)$ & $12(10)$ & $11(7)$ & $5(4)$ & $4(1)$ & $7(7)$ & $13(10)$ & 29 (23) \\
\hline
\end{tabular}

genera, with the pectin-degrading strains the most diverse (18 genera), followed by the cellulose degraders (15 genera), chitin degraders (10 genera), phenanthrene degraders (10 genera), and fluoranthene degraders ( 7 genera; Figure 6). Among them, 41 isolates belonging to 15 genera showed activity toward more than one organic substance. Nearly half of the degrading isolates were distributed in four genera, which were Kocuria (14 strains), Microbacterium (13 strains), Rhodococcus (12 strains), and Streptomyces (9 strains); and isolates classified within each of the genera Brevibacterium, Kocuria, and Rhodococcus showed degradation activity toward all of the organics tested. Almost all of the Streptomyces isolates showed activities toward cellulose ( 8 of 9) and chitin (9 of 9). Pectin degraders were mainly from the genera Kocuria, Microbacterium, Rhodococcus, and Streptomyces, of which Rhodococcus also accounted for $>1 / 3$ of the fluoranthene degraders (Figure 6). Cellulolytic and pectinolytic strains could be found in all nine samples. Furthermore, 9 of the 11 isolates and all 7 genera from M8 could degrade the organics, showing the highest activity rate among the samples (Table 4).

\section{DISCUSSION}

The results showed a high diversity and a relatively comprehensive community structure of actinobacteria in 
the deep-sea surface sediments and water along the SWIR, which significantly correlated with environmental factors. The biodegradation activity toward refractory organics demonstrated by most of the diverse actinobacterial isolates suggests their potential ecological functions and biotechnological uses.

\section{Actinobacteria in the Deep Sea along the SWIR are Highly Diverse}

The 16S rRNA gene pyrosequencing data showed that the relative abundance of actinobacteria in the sediments collected from the SWIR was higher than that found in the sediments of the deep Arctic and Atlantic Oceans (0.1-3.0\%, 0-2.32 mbsf), but less than that reported in the deep Pacific Ocean (about 10\%, 0-350 mbsf) (Inagaki et al., 2006; Schauer et al., 2010; Jorgensen et al., 2012). Our results also indicate that many unclassified actinobacterial taxa may exist in the deep sea along the SWIR, particularly in the surface sediments in non-hydrothermal fields (Figures 3, 7, Figures S1, S2). While $>80 \%$ of the actinobacterial unclassified reads were assigned to Acidimicrobiales OM1 clade using the SILVA database, most of these sequences, according to the recent data of Yilmaz et al. (2016), should belong to the uncultured Actinobacteria.Order3 which is distinct from the OM1 clade (Actinobacteria.Order2 in Yilmaz et al., 2016). Most of the remaining sequences were assigned into the classes Actinobacteria, similar to that reported for the surface sediments of the deep Arctic Ocean (Zhang et al., 2014). Members of the two classes have been reported to be widely distributed in various habitats; however, only members of Actinobacteria have been frequently isolated from the marine environment (Maldonado et al., 2005; Duncan et al., 2014; Zhang et al., 2014), which is also the case in our study. Most members of the class Acidimicrobiia are uncultured, and Acidimicrobiaceae, and Iamiaceae are the only two described families in this class (Jensen and Lauro, 2008; Goodfellow et al., 2012). Therefore, it is not strange to find in our study that a large number of the sequences of Acidimicrobiia could not be classified into a known family and Iamiaceae, a neutrophilic family, presented in eight samples including both the sediments and the bottom water. Interestingly, Acidimicrobiaceae, members of which prefer to grow at around pH 2 and have been isolated only from geothermal sites and acidic mine waters (Goodfellow et al., 2012), also occurred in all the SWIR sediment samples with non-negligible percentages (0.7-4.6\%, Figure S2), although the $\mathrm{pH}$ of the samples was 7.77-9.11 (Table 1).

Compared to the results of previous studies on marine actinobacterial diversity, which reported only 4-12 genera or 14 families, much more genera and families were detected in the actinobacterial community at the SWIR using either pyrosequencing or cultivation method (Figure 4, Table S2), with at least 66 known genera and 33 families detected in total (Figure 4). Most of the marine actinobacterial genera and families detected in previous studies were recovered in our results (Figure 4, Table S2), but the most abundant genera detected in deep Arctic marine surface sediments were largely different from those identified here (Table S2). Moreover, most of the known genera (46 of 66) detected at the SWIR were likely to be non-filamentous based on the previous descriptions (Goodfellow et al., 2012), similar to the finding in deep Arctic marine surface sediments (Zhang et al., 2014). In agreement with this result, most of our isolates (74.4\%) were non-filamentous actinobacteria, an observation in contrast to previous reports on shallow sediments, where filamentous actinobacteria, especially Micromonospora, Pseudonocardia, and Streptomyces, were most frequently cultivated (Maldonado et al., 2005; Bredholdt et al., 2007; Zhang et al., 2014). This difference might primarily result from the change in hydrostatic pressure, which is an important parameter in shaping the microbial community structure in the ocean and leads to small cocci being the most abundant morphotype of high-pressure-surviving microbes (Marietou and Bartlett, 2014). In addition, 53 isolates showed $<99 \% 16 \mathrm{~S}$ rRNA gene similarity to their closest type strains and therefore likely represented novel species according to the recommended cutoff value for actinobacterial species delineation (Stach et al., 2003a).

\section{The Actinobacterial Community Structure at the SWIR Significantly Correlates to Environmental Factors}

Researchers have gradually formed a consensus on the biogeography of marine actinobacteria (Ward and Bora, 2006). However, the related factors that contribute to shape the actinobacterial community structure, especially in the deep ocean, are still not clear. This study showed that $\mathrm{pH}$ and Ca were significant factors along the SWIR, whether the two hydrothermal field samples, M8 and M9, were considered or not. It has been demonstrated that $\mathrm{pH}$ was an important contributor to actinobacterial/prokaryotic community variations in soil ( $\mathrm{pH} 3.5-8.8)$, salt lakes ( $\mathrm{pH} 7.5-10.5)$, and hot springs $(\mathrm{pH}$ 5.0-10.0; Lauber et al., 2009; Pagaling et al., 2009; Valverde et al., 2012). In our study, a less-massive change in $\mathrm{pH}$ from 7.47 to 9.11 demonstrated a significantly high influence on the actinobacterial community structure (Table 3 ), indicating that the deep-sea actinobacterial composition is sensitive to $\mathrm{pH}$. This result was further supported by the evidence that $\mathrm{pH}$ significantly affected the relative abundance of the class Actinobactreia, the orders Corynebacteriales, Micrococcales, and Propionibacteriales, the families Micrococcaceae and Propionibacteriaceae, and unclassified Actinobacteria (both class and phylum) at the SWIR. It was not unexpected that $\mathrm{Ca}$, which was an essential nutrient and involved in $\mathrm{pH}$ buffering, was an environmental determinant of the community structure as well. Our study also showed for the first time that TOC, TP, and TN, which represented nutrients, were significantly correlated to actinobacterial community structure in the deep sea. Dissolved organic carbon and TP were previously reported to be related to the freshwater actinobacterial community structure in the brackish northern Baltic Sea (Holmfeldt et al., 2009). Total carbon, TN, and P were also reported to be significantly correlated to the relative abundance of actinobacteria in soils (Liu et al., 2014; Zhao et al., 2014). Taken together, $\mathrm{pH}$ and the above mentioned nutrients are likely to be the common factors that shape actinobacterial community structures in different habitats. Interestingly, some environmental variables significantly influenced the 
relative abundance of a few unclassified actinobacterial groups (Figure S4). This finding suggests that the responses of these unknown taxa, particularly the specific OTUs that were more influenced, to local environments may relate to their critical requirements for $\mathrm{pH}$ and nutrients.

The observation that the actinobacterial community structure was not affected by the geographic distance might be attributed to the fact that many actinobacteria can produce stress-resistant spores and possess various metabolic capabilities, characteristics that promoted their long-distance dispersal and survival in the resultant conditions encountered. Nevertheless, this observation may be also due to that our samples were not collected at a large spatial scale ( $<1000 \mathrm{~km}$ in geographic distance), because the scale of sampling was suggested to affect the relative contributions of spatial distance and environmental factors to microbial distribution (Martiny et al., 2006, 2011). Hence, extensive sampling at a larger geographic scale with more hydrothermal fields is still needed to determine whether actinobacterial distribution along the Indian Ridge and even the global deep ocean is controlled by historical or contemporary environmental factors or both.

\section{Actinobacteria from the SWIR Show Potential Ecological Functions and Biotechnological Applications}

Although, the concentrations of PAHs and polysaccharides of the samples were not determined in this study due to the difficulty of sampling and the limited amount of samples we obtained, these organics have been reported to be common in the deep ocean (Simoneit and Fetzer, 1996; Dong et al., 2015). More than half of the actinobacterial isolates obtained from this research showed the capacity to degrade organic matter, suggesting that actinobacteria may contribute to the substance and energy flows in biogeochemical cycles in the deep ocean. We found a high diversity of the marine actinobacterial degraders, with 20 polysaccharide-degrading genera and $12 \mathrm{PAH}$-degrading genera (Figure 6). Most of these genera, with the exception of Streptomyces, Nocardiopsis, and Dietzia, have not been reported to contain members inhabiting deep-sea environments whilst possessing organic degradation capacity. The genera that could degrade different refractory organics may have a better chance to thrive in a range of deep-sea habitats, as exemplified by Kocuria, Microbacterium, Mycobacterium, Rhodococcus, and Streptomyces, which spread in most of the samples as indicated by the combined results of culture-dependent and -independent analyses. Hydrolytic enzyme profiles have been analyzed for marine actinobacteria from shallow sediments, and the results indicated that Streptomyces had a better ability than the other genera to degrade cellulose, chitin, and pectin (Veiga et al., 1983; Augustine et al., 2013). Among the 23 degrading genera we obtained, Streptomyces was again the most important contributor to the degradation of chitin and cellulose. The result that all of the Streptomyces isolates could degrade chitin is consistent with the report that a Streptomyces strain has at least one and usually multiple chitinase genes and genes of the chitin-binding proteins are also widely distributed in Streptomyces (Williamson et al.,
2000). The observation that seven and ten actinobacterial genera in this study could degrade fluoranthene and phenanthrene, respectively, suggested a potential for discovering highly-efficient $\mathrm{PAH}$ degraders, which may fuel further research into the biodiversity of PAH-degrading actinobacteria in the deep marine environments.

The high abundance of the order Corynebacteriales in the hydrothermal field sediment M8 may be explained by the fact that many members of Corynebacteriales are degraders of xenobiotica (e.g., PAHs) and excellent survivors of unfavorable conditions (Bock et al., 1996; Willumsen et al., 2001). PAHs and heptaheptacontane are common in hydrothermal sediments (Simoneit and Fetzer, 1996), and the genera Gordonia, Mycobacterium, Rhodococcus, and Tsukamurella within Corynebacteriales have been reported to be highly efficient hydrocarbon degraders (Peczynska-Czoch and Mordarski, 1988; Daane et al., 2001; García-Díaz et al., 2013). This is also supported by the cultivation results of our study, where all five genera (Dietzia, Mycobacterium, Rhodococcus, Tsukamurella, and Williamsia) of Corynebacteriales demonstrated PAH degradation activity (Figure 6).

As most of the secondary metabolite-producing actinobacteria were filamentous (so-called actinomycetes; Tiwari and Gupta, 2012), while most of our actinobacterial isolates were nonfilamentous, we did not focus on bioactive compounds of the isolates in this study. Actually we had conducted a primary screening of antimicrobial activity on 37 isolates of nine genera and found that only two isolates belonged to Micromonospora and Streptomyces, respectively, showed inhibitory activity against Micrococcus luteus only. Given the high biodegradation activity of the diverse isolates, it is likely that the ability to utilize refractory organics is important for the survival of actinobacteria in the deep sea. Recent PICRUSt predictions for the uncultured actinobacterial orders in deep pelagic zones also suggested their potential for refractory organic degradation in terms of carbon metabolism (Yilmaz et al., 2016). This characteristic implied the potential roles of actinobacteria in the recycling of organic matter in the deep-sea environments, which might enhance their competitive ability in situ.

\section{AUTHOR CONTRIBUTIONS}

YH, PC, XD, and LH designed the study. LS collected the samples. PC, LZ, XG, LX, and YZ conducted the lab work. PC, YH, LL, $\mathrm{YW}$, and JW analyzed the data. YH, PC, XD, and LH wrote the paper.

\section{ACKNOWLEDGMENTS}

This research was supported by the China Ocean Mineral Resources R \& D Association (DY125-15-R-02) and the National Science Foundation of China (31470142 and 41306164). We thank Dr. Xiao-Yang Zhi at the Yunnan University for assistance with pyrosequencing data processing using QIIME. 


\section{SUPPLEMENTARY MATERIAL}

The Supplementary Material for this article can be found online at: http://journal.frontiersin.org/article/10.3389/fmicb. 2016.01340

Figure S1 | Actinobacterial community compositions at the class rank in the samples. The relative abundance represents the proportional frequencies of actinobacterial reads that were classified or unclassified at the class rank, using the RDP classifier, based on the hierarchical classification in the second edition of Bergey's Manual of Systematic Bacteriology (Goodfellow et al., 2012).

Figure S2 | Actinobacterial community compositions at the family rank in the samples. The relative abundance represents the proportional frequencies of actinobacterial reads that were classified or unclassified at the family rank, using the RDP classifier, based on the hierarchical classification in the second edition of Bergey's Manual of Systematic Bacteriology (Goodfellow et al., 2012). The most abundant families are shown in bold.

\section{REFERENCES}

Augustine, D., Jacob, J. C., Ramya, K., and Philip, R. (2013). Actinobacteria from sediment samples of Arabian Sea and Bay of Bengal: biochemical and physiological characterization. Int. J. Res. Mar. Sci. 2, 56-63. Available online at: http://www.urpjournals.com/tocjnls/37_13v2i2_5.pdf

Baker, E. T., German, C. R., and Elderfield, H. (1995). Hydrothermal plumes over spreading-center axes: global distributions and geological inferences. Geoph. Monog. Series. 91, 47-71. doi: 10.1029/gm091p0047

Baker, G., Smith, J., and Cowan, D. A. (2003). Review and re-analysis of domain-specific 16S primers. J. Microbiol. Methods 55, 541-555. doi: 10.1016/j.mimet.2003.08.009

Bock, C., Kroppenstedt, R., Schmidt, U., and Diekmann, H. (1996). Degradation of prochloraz and 2, 4, 6-trichlorophenol by environmental bacterial strains. Appl. Microbiol. Biotehnol. 45, 257-262. doi: 10.1007/s002530050680

Borcard, D., Legendre, P., and Drapeau, P. (1992). Partialling out the spatial component of ecological variation. Ecology 73, 1045-1055. doi: 10.2307/194 0179

Bredholdt, H., Galatenko, O. A., Engelhardt, K., Fjærvik, E., Terekhova, L. P., and Zotchev, S. B. (2007). Rare actinomycete bacteria from the shallow water sediments of the Trondheim fjord, Norway: isolation, diversity and biological activity. Environ. Microbiol. 9, 2756-2764. doi: 10.1111/j.14622920.2007.01387.x

Bull, A. T. (2011). "Actinobacteria of the extremobiosphere," in Extremophiles Handbook, eds K. Horikoshi, G. Antranikian, A. T. Bull, F. Robb, and K. Stelter (Berlin: Springer), 1203-1240.

Cao, H., Wang, Y., Lee, O. O., Zeng, X., Shao, Z., and Qian, P. Y. (2014). Microbial sulfur cycle in two hydrothermal chimneys on the Southwest Indian Ridge. mBio 5, e00980-e00913. doi: 10.1128/mBio.00980-13

Caporaso, J. G., Bittinger, K., Bushman, F. D., DeSantis, T. Z., Andersen, G. L., and Knight, R. (2010a). PyNAST: a flexible tool for aligning sequences to a template alignment. Bioinformatics 26, 266-267. doi: 10.1093/bioinformatics/btp636

Caporaso, J. G., Kuczynski, J., Stombaugh, J., Bittinger, K., Bushman, F. D., Costello, E. K., et al. (2010b). QIIME allows analysis of high-throughput community sequencing data. Nat. Methods. 7, 335-336. doi: 10.1038/nmeth. f.303

Carter, M. R., and Gregorich, E. G. (2008). Soil Sampling and Methods of Analysis. Boca Raton, FL: CRC Press.

Chun, J., and Goodfellow, M. (1995). A phylogenetic analysis of the genus Nocardia with 16S rRNA gene sequences. Int. J. Syst. Bacteriol. 45, 240-245. doi: 10.1099/00207713-45-2-240

Cole, J. R., Wang, Q., Fish, J. A., Chai, B., McGarrell, D. M., Sun, Y., et al. (2013). Ribosomal database project: data and tools for high throughput rRNA analysis. Nucleic Acids Res. 42, D633-D642. doi: 10.1093/nar/gkt1244

Daane, L., Harjono, I., Zylstra, G., and Häggblom, M. (2001). Isolation and characterization of polycyclic aromatic hydrocarbon-degrading bacteria associated with the rhizosphere of salt marsh plants. Appl. Environ. Microbiol. 67, 2683-2691. doi: 10.1128/AEM.67.6.2683-2691.2001
Figure S3 | PCoA representing the similarity of the actinobacterial community compositions in the samples detected by pyrosequencing at the $\mathbf{0 . 0 3}$ OTU level.

Figure S4 | The relationships between the relative abundance of some of the major groups of actinobacteria and environmental factors. EC, electric conductance; TN, total nitrogen; NO-N, nitrate nitrogen.

Figure S5 | Parts of the zoom-in phylogenetic tree of Figure 7 showing the relationships between the 14 Acidimicrobiia clades and the OM1 clade. Taxonomic assignments of the sequences were based on both the RDP and SILVA databases. Numbers at branch nodes are percentages of bootstrap replicates of 100 resamplings (only values above 50\% are shown). Numbers in the parentheses following each clade indicate the relative abundance of pyrosequencing reads and isolates, respectively. Bar $=$ nucleotide changes per site.

\section{Table S1 | The geographical distance matrix.}

Table S2 | Summary of the analyses on actinobacterial diversity in shallow and deep seas using culture-dependent and -independent methods.

Darriba, D., Taboada, G. L., Doallo, R., and Posada, D. (2012). jModelTest 2: more models, new heuristics and parallel computing. Nat. Methods 9, 772-772. doi: 10.1038/nmeth.2109

DeSantis, T. Z., Hugenholtz, P., Larsen, N., Rojas, M., Brodie, E. L., Keller, K., et al. (2006). Greengenes, a chimera-checked 16S rRNA gene database and workbench compatible with ARB. Appl. Environ. Microbiol. 72, 5069-5072. doi: 10.1128/AEM.03006-05

Dong, C., Bai, X., Sheng, H., Jiao, L., Zhou, H., and Shao, Z. (2015). Distribution of PAHs and the PAH-degrading bacteria in the deep-sea sediments of the high-latitude Arctic Ocean. Biogeosciences 12, 2163-2177. doi: 10.5194/bg-122163-2015

Duncan, K., Haltli, B., Gill, K. A., and Kerr, R. G. (2014). Bioprospecting from marine sediments of New Brunswick, Canada: exploring the relationship between total bacterial diversity and actinobacteria diversity. Mar. Drugs 12, 899-925. doi: 10.3390/md12020899

Edgar, R. C. (2010). Search and clustering orders of magnitude faster than BLAST. Bioinformatics 26, 2460-2461. doi: 10.1093/bioinformatics/btq461

Ensign, J. C. (1992). "Introduction to the actinomycetes," in The prokaryotes, 2nd Edn., Vol. 1, eds A. Belows, H. G. Trüper, M. Dworkin, W. Harder, and K. H. Schleifer (Berlin; Heidelberg; New York, NY: Springer), 811-815.

Felsenstein, J. (1981). Evolutionary trees from DNA sequences: a maximum likelihood approach. J. Mol. Evol. 17, 368-376. doi: 10.1007/BF01734359

Felsenstein, J. (1985). Confidence limits on phylogenies: an approach using the bootstrap. Evolution 39, 783-791. doi: 10.2307/2408678

García-Díaz, C., Ponce-Noyola, M. T., Esparza-García, F., Rivera-Orduña, F., and Barrera-Cortés, J. (2013). PAH removal of high molecular weight by characterized bacterial strains from different organic sources. Int. Biodeter. Biodegr. 85, 311-322. doi: 10.1016/j.ibiod.2013.08.016

German, C., Baker, E., Mevel, C., and Tamaki, K. (1998). Hydrothermal activity along the southwest Indian ridge. Nature 395, 490-493. doi: 10.1038/26730

Goodfellow, M., and Fiedler, H.-P. (2010). A guide to successful bioprospecting: informed by actinobacterial systematics. Antonie van Leeuwenhoek 98, 119-142. doi: 10.1007/s10482-010-9460-2

Goodfellow, M., Kämpfer., P., Busse., H.-J., Trujillo, M. E., Suzuki, K.-I., Ludwig, W., et al. (2012). Bergey's Manual of Systematic Bacteriology, 2nd Edn., Vol. 5: The Actinobacteria. New York, NY: Springer.

Guo, Y., Zheng, W., Rong, X., and Huang, Y. (2008). A multilocus phylogeny of the Streptomyces griseus 16S rRNA gene clade: use of multilocus sequence analysis for streptomycete systematics. Int. J. Syst. Evol. Microbiol. 58, 149-159. doi: 10.1099/ijs.0.65224-0

Haas, B. J., Gevers, D., Earl, A. M., Feldgarden, M., Ward, D. V., Giannoukos, G., et al. (2011). Chimeric 16S rRNA sequence formation and detection in Sanger and 454-pyrosequenced PCR amplicons. Genome. Res. 21, 494-504. doi: $10.1101 /$ gr.112730.110

Hamady, M., Lozupone, C., and Knight, R. (2010). Fast UniFrac: facilitating high-throughput phylogenetic analyses of microbial communities including analysis of pyrosequencing and PhyloChip data. ISME J. 4, 17-27. doi: 10.1038/ismej.2009.97 
Hill, M. O., and Gauch, H. G. Jr. (1980). Detrended correspondence analysis: an improved ordination technique. Vegetatio 42, 47-58. doi: 10.1007/BF00048870

Holmfeldt, K., Dziallas, C., Titelman, J., Pohlmann, K., Grossart, H. P., and Riemann, L. (2009). Diversity and abundance of freshwater Actinobacteria along environmental gradients in the brackish northern Baltic Sea. Environ. Microbiol. 11, 2042-2054. doi: 10.1111/j.1462-2920.2009.01925.x

Hopkins, D., Macnaughton, S., and O'Donnell, A. (1991). A dispersion and differential centrifugation technique for representatively sampling microorganisms from soil. Soil Biol. Biochem. 23, 217-225. doi: 10.1016/00380717(91)90055-O

Huse, S. M., Huber, J. A., Morrison, H. G., Sogin, M. L., and Welch, D. M. (2007). Accuracy and quality of massively parallel DNA pyrosequencing. Genome Biol. 8:1. doi: 10.1186/gb-2007-8-7-r143

Inagaki, F., Nunoura, T., Nakagawa, S., Teske, A., Lever, M., Lauer, A., et al. (2006). Biogeographical distribution and diversity of microbes in methane hydratebearing deep marine sediments on the Pacific Ocean Margin. Proc. Natl. Acad. Sci. U.S.A. 103, 2815-2820. doi: 10.1073/pnas.0511033103

Jannasch, H. W., and Mottl, M. J. (1985). Geomicrobiology of deepsea hydrothermal vents. Science 229, 717-725. doi: 10.1126/science.229.47 15.717

Janssen, P. H., Schuhmann, A., Mörschel, E., and Rainey, F. A. (1997). Novel anaerobic ultramicrobacteria belonging to the Verrucomicrobiales lineage of bacterial descent isolated by dilution culture from anoxic rice paddy soil. Appl. Environ. Microbiol. 63, 1382-1388.

Jensen, P. R., Gontang, E., Mafnas, C., Mincer, T. J., and Fenical, W. (2005). Culturable marine actinomycete diversity from tropical Pacific Ocean sediments. Environ. Microbiol. 7, 1039-1048. doi: 10.1111/j.14622920.2005.00785.x

Jensen, P. R., and Lauro, F. M. (2008). An assessment of actinobacterial diversity in the marine environment. Antonie van Leeuwenhoek 94, 51-62. doi: 10.1007/s10482-008-9239-x

Jorgensen, S. L., Hannisdal, B., Lanzén, A., Baumberger, T., Flesland, K., Fonseca, R., et al. (2012). Correlating microbial community profiles with geochemical data in highly stratified sediments from the Arctic Mid-Ocean Ridge. Proc. Natl. Acad. Sci. U.S.A. 109, e2846-e2855. doi: 10.1073/pnas. 1207574109

Kiyohara, H., Nagao, K., and Yana, K. (1982). Rapid screen for bacteria degrading water-insoluble, solid hydrocarbons on agar plates. Appl. Environ. Microbiol. 43, 454-457.

Klindworth, A., Pruesse, E., Schweer, T., Peplies, J., Quast, C., Horn, M., et al. (2012). Evaluation of general 16S ribosomal RNA gene PCR primers for classical and next-generation sequencing-based diversity studies. Nucleic Acids Res. 41:e1. doi: 10.1093/nar/gks808

Lane, D. (1991). "16S/23S rRNA sequencing," in Nucleic Acid Techniques in Bacterial Systematics, eds E. Stackebrandt and M. Goodfellow (Chichester: John Wiley \& Sons), 115-175.

Latimer, J. S., and Zheng, J. (2003). "The sources, transport, and fate of PAHs in the marine environment," in PAHs: An Ecotoxicological Perspective, ed P. E. T. Douben (Chichester: John Wiley \& Sons, Ltd), 7-33.

Lauber, C. L., Hamady, M., Knight, R., and Fierer, N. (2009). Pyrosequencingbased assessment of soil $\mathrm{pH}$ as a predictor of soil bacterial community structure at the continental scale. Appl. Environ. Microbiol. 75, 5111-5120. doi: 10.1128/AEM.00335-09

Lee, O. O., Wang, Y., Yang, J., Lafi, F. F., Al-Suwailem, A., and Qian, P.-Y. (2010). Pyrosequencing reveals highly diverse and species-specific microbial communities in sponges from the Red Sea. ISME J. 5, 650-664. doi: 10.1038/ismej.2010.165

Lepš, J., and Šmilauer, P. (2003). Multivariate Analysis of Ecological Data using CANOCO. Cambridge, UK: Cambridge University Press.

Li, J., Peng, X., Zhou, H., Li, J., Sun, Z., and Chen, S. (2014). Microbial communities in semi-consolidated carbonate sediments of the Southwest Indian Ridge. J. Microbiol. 52, 111-119. doi: 10.1007/s12275-014-3133-1

Liu, J., Sui, Y., Yu, Z., Shi, Y., Chu, H., Jin, J., et al. (2014). High throughput sequencing analysis of biogeographical distribution of bacterial communities in the black soils of northeast China. Soil. Biol. Biochem. 70, 113-122. doi: 10.1016/j.soilbio.2013.12.014

López-García, P., Duperron, S., Philippot, P., Foriel, J., Susini, J., and Moreira, D. (2003). Bacterial diversity in hydrothermal sediment and epsilonproteobacterial dominance in experimental microcolonizers at the
Mid-Atlantic Ridge. Environ. Microbiol. 5, 961-976. doi: 10.1046/j.14622920.2003.00495.x

Maldonado, L. A., Stach, J. E., Pathom-aree, W., Ward, A. C., Bull, A. T., and Goodfellow, M. (2005). Diversity of cultivable actinobacteria in geographically widespread marine sediments. Antonie van Leeuwenhoek 87, 11-18. doi: 10.1007/s10482-004-6525-0

Manucharova, N. (2009). The microbial destruction of chitin, pectin, and cellulose in soils. Eurasian Soil Sci. 42, 1526-1532. doi: 10.1134/S1064229309130146

Marietou, A., and Bartlett, D. H. (2014). Effects of high hydrostatic pressure on coastal bacterial community abundance and diversity. Appl. Environ. Microbiol. 80, 5992-6003. doi: 10.1128/AEM.02109-14

Martiny, J. B., Eisen, J. A., Penn, K., Allison, S. D., and Horner-Devine, M. C. (2011). Drivers of bacterial $\beta$-diversity depend on spatial scale. Proc. Natl. Acad. Sci. U.S.A. 108, 7850-7854. doi: 10.1073/pnas.1016308108

Martiny, J. B. H., Bohannan, B. J., Brown, J. H., Colwell, R. K., Fuhrman, J. A., Green, J. L., et al. (2006). Microbial biogeography: putting microorganisms on the map. Nat. Rev. Microbiol. 4, 102-112. doi: 10.1038/nrmicro1341

Oksanen, J., Blanchet, F., Kindt, R., Legendre, P., O’Hara, R., Simpson, G., et al. (2013). Vegan: Community Ecology Package. R package version 2.0-10. Available online at: http://CRAN.R-project.org/package=vegan

Orsi, W. D., Edgcomb, V. P., Christman, G. D., and Biddle, J. F. (2013). Gene expression in the deep biosphere. Nature 499, 205-208. doi: 10.1038 /nature 12230

Pagaling, E., Wang, H., Venables, M., Wallace, A., Grant, W. D., Cowan, D. A., et al. (2009). Microbial biogeography of six salt lakes in Inner Mongolia, China, and a salt lake in Argentina. Appl. Environ. Microbiol. 75, 5750-5760. doi: 10.1128/AEM.00040-09

Peczynska-Czoch, W., and Mordarski, M. (1988). "Actinomycete enzymes," in Actinomycetes in Biotechnology, eds M. Goodfellow, S. T. Williams, and M. Mordarski (London: Academic Press), 219-283.

Pommier, T., Canbäck, B., Riemann, L., Boström, K., Simu, K., Lundberg, P., et al. (2007). Global patterns of diversity and community structure in marine bacterioplankton. Mol. Ecol. 16, 867-880. doi: 10.1111/j.1365294X.2006.03189.x

Price, M. N., Dehal, P. S., and Arkin, A. P. (2010). FastTree 2-approximately maximum-likelihood trees for large alignments. PloS ONE 5:e9490. doi: 10.1371/journal.pone.0009490

Prieto-Davó, A., Villarreal-Gomez, L. J., Forschner-Dancause, S., Bull, A. T., Stach, J. E., Smith, D. C., et al. (2013). Targeted search for actinomycetes from nearshore and deep-sea marine sediments. FEMS Microbiol. Ecol. 84, 510-518. doi: 10.1111/1574-6941.12082

Pruesse, E., Peplies, J., and Glöckner, F. O. (2012). SINA: accurate high-throughput multiple sequence alignment of ribosomal RNA genes. Bioinformatics 28, 1823-1829. doi: 10.1093/bioinformatics/bts252

Qiu, D., Ruan, J., and Huang, Y. (2008). Selective isolation and rapid identification of members of the genus Micromonospora. Appl. Environ. Microbiol. 74, 5593-5597. doi: 10.1128/AEM.00303-08

Schäfer, J., Jackel, U., and Kämpfer, P. (2010). Development of a new PCR primer system for selective amplification of Actinobacteria. FEMS Microbiol. Lett. 311, 103-112. doi: 10.1111/j.1574-6968.2010.02069.x

Schauer, R., Bienhold, C., Ramette, A., and Harder, J. (2010). Bacterial diversity and biogeography in deep-sea surface sediments of the South Atlantic Ocean. ISME J. 4, 159-170. doi: 10.1038/ismej.2009.106

Shirling, E. B., and Gottlieb, D. (1966). Methods for characterization of Streptomyces species. Int. J. Syst. Bacteriol. 16, 313-340 doi: 10.1099/0020771316-3-313

Simoneit, B. R., and Fetzer, J. C. (1996). High molecular weight polycyclic aromatic hydrocarbons in hydrothermal petroleums from the Gulf of California and Northeast Pacific Ocean. Org. Geochem. 24, 1065-1077. doi: 10.1016/S01466380(96)00081-2

Stach, J. E., Maldonado, L. A., Masson, D. G., Ward, A. C., Goodfellow, M., and Bull, A. T. (2003a). Statistical approaches for estimating actinobacterial diversity in marine sediments. Appl. Environ. Microbiol. 69, 6189-6200. doi: 10.1128/AEM.69.10.6189-6200.2003

Stach, J. E., Maldonado, L. A., Ward, A. C., Goodfellow, M., and Bull, A. T. (2003b). New primers for the class Actinobacteria: application to marine and terrestrial environments. Environ. Microbiol. 5, 828-841. doi: 10.1046/j.14622920.2003.00483.x 
Stamatakis, A. (2006). RAxML-VI-HPC: maximum likelihoodbased phylogenetic analyses with thousands of taxa and mixed models. Bioinformatics 22, 2688-2690. doi: 10.1093/bioinformatics/ btl446

Tamura, K., Peterson, D., Peterson, N., Stecher, G., Nei, M., and Kumar, S. (2011). MEGA5: molecular evolutionary genetics analysis using maximum likelihood, evolutionary distance, and maximum parsimony methods. Mol. Biol. Evol. 28, 2731-2739. doi: 10.1093/molbev/msr121

Tao, C., Li, H., Jin, X., Zhou, J., Wu, T., He, Y., et al. (2014). Seafloor hydrothermal activity and polymetallic sulfide exploration on the southwest Indian ridge. Chin. Sci. Bull. 59, 2266-2276. doi: 10.1007/s11434-0140182-0

Tao, C., Lin, J., Guo, S., Chen, Y. J., Wu, G., Han, X., et al. (2012). First active hydrothermal vents on an ultraslow-spreading center: Southwest Indian Ridge. Geology 40, 47-50. doi: 10.1130/G32389.1

Team, R. C. (2014). R: A language and Environment for Statistical Computing. Vienna. $\mathrm{R}$ Foundation for Statistical Computing. Availabe online at: http://www.R-project.org/

Ter Braak, C. J. (1986). Canonical correspondence analysis: a new eigenvector technique for multivariate direct gradient analysis. Ecology 67, 1167-1179. doi: $10.2307 / 1938672$

Teske, A., Hinrichs, K.-U., Edgcomb, V., de Vera Gomez, A., Kysela, D., Sylva, S. P., et al. (2002). Microbial diversity of hydrothermal sediments in the Guaymas Basin: evidence for anaerobic methanotrophic communities. Appl. Environ. Microbiol. 68, 1994-2007. doi: 10.1128/AEM.68.4.1994-2007.2002

Tiwari, K., and Gupta, R. K. (2012). Rare actinomycetes: a potential storehouse for novel antibiotics. Crit. Rev. Biotechnol. 32, 108-132. doi: 10.3109/07388551.2011.562482

Uyttebroek, M., Breugelmans, P., Janssen, M., Wattiau, P., Joffe, B., Karlson, U., et al. (2006). Distribution of the Mycobacterium community and polycyclic aromatic hydrocarbons (PAHs) among different size fractions of a long-term PAH-contaminated soil. Environ. Microbiol. 8, 836-847. doi: 10.1111/j.14622920.2005.00970.x

Valverde, A., Tuffin, M., and Cowan, D. A. (2012). Biogeography of bacterial communities in hot springs: a focus on the actinobacteria. Extremophiles 16, 669-679. doi: 10.1007/s00792-012-0465-9

Veiga, M., Esparis, A., and Fabregas, J. (1983). Isolation of cellulolytic actinomycetes from marine sediments. Appl. Environ. Microbiol. 46, 286.

Wang, Q., Garrity, G. M., Tiedje, J. M., and Cole, J. R. (2007). Naive Bayesian classifier for rapid assignment of rRNA sequences into the new bacterial taxonomy. Appl. Environ. Microbiol. 73, 5261-5267. doi: 10.1128/AEM.00 062-07

Ward, A. C., and Bora, N. (2006). Diversity and biogeography of marine actinobacteria. Curr. Opin. Microbiol. 9, 279-286. doi: 10.1016/j.mib.2006. 04.004
Wessel, P., and Smith, W. H. (1998). New, improved version of generic mapping tools released. Eos. Trans. Amer. Geophys. Union 79, 579. doi: 10.1029/98EO00426

Williamson, N., Brian, P., and Wellington, E. (2000). Molecular detection of bacterial and streptomycete chitinases in the environment. Antonie Van Leeuwenhoek 78, 315-321. doi: 10.1023/A:1010225909148

Willumsen, P., Karlson, U., Stackebrandt, E., and Kroppenstedt, R. M. (2001). Mycobacterium frederiksbergense sp. nov., a novel polycyclic aromatic hydrocarbon-degrading Mycobacterium species. Int. J. Syst. Evol. Micr. 51, 1715-1722. doi: 10.1099/00207713-51-5-1715

Yang, Y., Gao, Y., Wang, S., Xu, D., Yu, H., Wu, L., et al. (2014). The microbial gene diversity along an elevation gradient of the Tibetan grassland. ISME J. 8, 430-440. doi: 10.1038/ismej.2013.146

Yilmaz, P., Yarza, P., Rapp, J. Z., and Glöckner, F. O. (2016). Expanding the world of marine bacterial and archaeal clades. Front. Microbiol. 6:1524. doi: 10.3389/fmicb.2015.01524

Zhang, G., Cao, T., Ying, J., Yang, Y., and Ma, L. (2014). Diversity and novelty of actinobacteria in Arctic marine sediments. Antonie Van Leeuwenhoek 105, 743-754. doi: 10.1007/s10482-014-0130-7

Zhang, H., Lee, Y. K., Zhang, W., and Lee, H. K. (2006). Culturable actinobacteria from the marine sponge Hymeniacidon perleve: isolation and phylogenetic diversity by $16 \mathrm{~S}$ rRNA gene-RFLP analysis. Antonie Van Leeuwenhoek 90 159-169. doi: 10.1007/s10482-006-9070-1

Zhao, J., Zhang, R., Xue, C., Xun, W., Sun, L., Xu, Y., et al. (2014). Pyrosequencing reveals contrasting soil bacterial diversity and community structure of two main winter wheat cropping systems in China. Microb. Ecol. 67, 443-453. doi: 10.1007/s00248-013-0322-0

Zhou, J., Bruns, M. A., and Tiedje, J. M. (1996). DNA recovery from soils of diverse composition. Appl. Environ. Microbiol. 62, 316-322.

Zinger, L., Amaral-Zettler, L. A., Fuhrman, J. A., Horner-Devine, M. C., Huse, S. M., Welch, D. B., et al. (2011). Global patterns of bacterial betadiversity in seafloor and seawater ecosystems. PloS ONE 6:e24570. doi: 10.1371/journal.pone.0024570

Conflict of Interest Statement: The authors declare that the research was conducted in the absence of any commercial or financial relationships that could be construed as a potential conflict of interest.

Copyright (C) 2016 Chen, Zhang, Guo, Dai, Liu, Xi, Wang, Song, Wang, Zhu, Huang and Huang. This is an open-access article distributed under the terms of the Creative Commons Attribution License (CC BY). The use, distribution or reproduction in other forums is permitted, provided the original author(s) or licensor are credited and that the original publication in this journal is cited, in accordance with accepted academic practice. No use, distribution or reproduction is permitted which does not comply with these terms. 